\title{
Optimum control parameters and long-term productivity of geothermal reservoirs using coupled thermo-hydraulic process modelling
}

\author{
Musa D. Aliyu ${ }^{1}$ and Hua-Peng Chen $^{1 *}$ \\ ${ }^{1}$ Department of Engineering Science, University of Greenwich, Chatham, \\ Kent ME4 4TB, U. K. \\ Email:m.d.aliyu@greenwich.ac.uk \\ *Corresponding author: H.Chen@greenwich.ac.uk
}

\begin{abstract}
Knowing the long-term performance of geothermal energy extraction is crucial to decisionmakers and reservoir engineers for optimal management and sustainable utilisation. This article presents a three-dimensional, numerical model of coupled thermo-hydraulic processes, in a deep heterogeneous geothermal reservoir overlain and underlain by impermeable layers, with discrete fracture. The finite element method is employed in modelling the reservoir, after conducting a verification study to test the capability of the solver and the results obtained are in agreement with the existing models. The model is then used to investigate the responses of human control parameters (injection flow rate, fluid injection temperature, and lateral well spacing) on reservoir productivity, using different operation scenarios. The injection flow rate is found to be more efficient, concerning reservoir productivity, than the other two parameters. To this end, the study concludes that, by varying some parameters in the subsurface, reservoir productivity can be optimised efficiently. The numerical model developed provides in-depth insight to stakeholders and reservoir engineers concerning the essential parameters to control during exploration and exploitation.
\end{abstract}

Keywords: geothermal energy extraction, coupled thermo-hydraulic, discrete fracture, finite element method, parameters analyses 


\section{Introduction}

Geothermal energy is a base load energy resource that is available universally beneath us in great quantity. One form of this resource is the deep geothermal system, from which energy is mined by forcing circulating fluids via an injection well to create a reservoir and then extracting the fluid back through a production well in a closed loop [1]-[4]. Before exploiting the energy, preliminary studies on the geological formations and petrophysical properties of a selected field needed to be conducted. However, field experiments are very expensive to perform [5], and the long-term performance of the systems should be investigated before engagement. Numerical modelling can provide essential information that will guide in determining the long-term performance of geothermal systems. To simulate and evaluate the behaviour of a deep geothermal system for its commercial viability, a reliable numerical method that can handle the complexity of subsurface flow is needed [6]. The modelling of geothermal systems has become a useful technology with applications to more than 100 fields worldwide [7]. Also, computational meshes of large, complex, three-dimensional models with more than 4000 blocks are now used routinely [7]. The first development of a geothermal reservoir simulation took place in the early 1970s [8]. However, the most accepted one in the geothermal industry was the 1980 code comparison exercise organised by the US Department of Energy [9], which consisted of testing several geothermal simulators on a set of six test problems. As a result, a progressive improvement in the capabilities of simulation codes for geothermal reservoir modelling has been acquired.

There have been substantial advances in numerical simulation for geothermal reservoirs over the past several decades, with the steady growth of computational power and the development of numerical models that have minimised several simplifying hypotheses. The advances include the implementation of more accurate equations of state for the fluid system, for instance, in the TOUGH2 and TOUGHREACT codes and the FALCON code [10]-[12]. Also, there has been tremendous progress in the ability to represent geometric complexity and heterogeneity in simulation codes; examples include FEFLOW, GOCAD, and OpenGeoSys [13], [14]. Computational schemes that are faster and more accurate have also been elaborated in reservoir simulation. Other numerical simulation codes are still under development, especially those by the current reservoir modelling working group, inaugurated with the help of the International Partnership for Geothermal Technology (IPGT). The IPGT is an international organisation with five member countries (Australia, Iceland, New Zealand, Switzerland, and the United States) aiming to improve understanding of geothermal potentials and usage in the globe [15]. The organisation proposed to develop a standard geothermal 
simulation code that will couple the various interactions arising during exploitation by the year 2020. The Geothermal Technology Office (GTO) under the Energy Department of the United States has initiated a code comparison study program that will improve the state of the art of geothermal simulation codes [16]. The program focused on examining existing codes, identifying dissimilarities, and illustrating the modelling capabilities of a global compilation of several numerical simulators for assessing geothermal technologies. Six benchmark problems were proposed, and the program commenced in 2014. According to White and Phillips [17], 12 groups participated in the challenge, and each group had a unique numerical simulator and analytical approaches providing a detailed mechanistic approach, modelling process, and solution scheme. Ghassemi et al. [18] reported on some of the outcomes of the program, stating that none of the 12 members was able to participate in all six problems due specifically to code limitations.

Therefore, geothermal modelling tools exist for several decades, but they were unable to cope with modern demands, both in resolving scientific and resource specific questions and in computational practicability [19]. Although concepts can be rigorously tested for consistency with data as soon as these become available, it is never early to establish a computational model [18]. An appropriate numerical modelling tool is vital in planning the energy extraction operations. The essential key instruments in planning the operations include parametric studies. Shook [21] conducted an extensive study on some naturally occurring parameters and their effect on energy recovery using the TETRAD code by employing the geysers' geothermal data. The parameters include capillary pressure and relative permeability relationship, initial liquid saturations, fracture spacing, and geologic structure. Nalla et al. [22] studied the effect of formation properties and operational variables of wellbore heat exchangers (WBHX) for enhanced geothermal systems (EGS) using the TETRAD simulation code. Vacchiarrelli et al. [23] carried out a parametric study on the effects of fracture aperture and fracture rotation angle on reservoir productivity by applying the GEOCRACK simulation code. Recently, Chen and Jiang [24] reported the heat extraction performance of EGS using different wellbore layout configurations. The layout investigated include doublet, triplet-straight line, triplet-triangle, and quintuplet. Jain et al. [25] examined the effect of various wellbore arrangements under different injection rates by employing the SHEEMAT simulation code. The injected rates employed were $50 \mathrm{l} / \mathrm{s}, 100 \mathrm{l} / \mathrm{s}$ and $150 \mathrm{l} / \mathrm{s}$, and the wellbore configurations studied include doublet, triplet, and reversed-triplet. Poulsen et al. [26] analysed the effect of thermal conductivity of confining beds, production rate, injection temperature, and reservoir thickness on the productivity of low enthalpy geothermal reservoirs. Aliyu et al. [27] studied 
the effect of extraction well placement on geothermal productivity using the dual porosity approach.

Especially, not much attention has been paid to the parametric studies on humancontrolled parameters in geothermal energy extraction. Bedre and Anderson [28] first introduced the idea by analysing naturally occurring parameters and human-controlled parameters of low-enthalpy geothermal systems in the United States using the 'One Factor At a Time' (OFAT) method. Saeid et al. [29] developed a prototype model capable of estimating the lifetime of low-enthalpy systems, based on the OFAT method proposed in [28]. In [28] the reservoir is represented as a three-dimensional (3-D) model with the assumption of a simplistic porous media approach for the fracture systems using the TOUGH2 five-spot model, whereas in [29], the contributions of fracture systems is ignored in their representation but an explicit 3D model of the reservoir is depicted with underlying and overburdened strata. It can be summarised from the above literature that the previous research focuses specifically on lowenthalpy geothermal systems, naturally occurring parameters, and stochastic modelling tools in the reservoir representations. Thus, not much has been reported on human-controlled parameters in geothermal energy extraction, more specifically on enhanced geothermal systems with open boundaries.

In this study, a 3-D numerical model of a deep and heterogeneous geothermal reservoir is developed with a discrete fracture using the Soultz EGS scheme. The system proposed here considers the influence of the surrounding media, the reservoir, and the fractures concurrently in the estimation of the effect of human control parameters on geothermal energy extraction. In this model, the fluid is circulated through an inclined vertical well connected to the matrix (i.e., not a fracture) in a fully saturated porous medium, unlike the previously reported models in which the injection and the production wells communicate via a single planar fracture or multiple. Although, a fracture is also included in this model that intersects the matrix at an angle but without connecting the wellbores to communicate. The reason for these assumptions in the current model is that sometimes the wellbores do not connect through fractures, as in the case of Soultz triplet geothermal reservoir where a low connection between GPK3 (injection well) and GPK4 (the second production well) is experienced due to calcite deposition [30]. Moreover, the geothermal reservoir is modelled as an open system that allows for additional sources or losses from the surrounding boundaries. As a result, water losses in the reservoir are accounted for in the model. The significance of this assumption can be supported by a real-life case of an existing geothermal reservoir. For instance, the five-month circulation test regarding hydraulics, conducted in the Soultz geothermal reservoir during 2005, showed that only $30 \%$ 
of fluid mass injected is recovered at the production wells, displaying the open nature of the reservoir [31]. The test result opposed the hot dry rock (HDR) concept that considered the reservoir to be a closed system with no naturally existing fluid present before its injection [32].

The contribution of the present work includes these three aspects. First, this study has proposed a mixed transport of fluid and heat in the reservoir from both the matrix block and the fracture, respectively. Second, the 3-D model takes into account the effect of fluid losses or gains concerning the nature of open systems in subsurface media, whose long-term influence on the extraction wellbore temperature cannot be underestimated for a 30-year extraction period. Third, in this investigation, each of the human-controlled parameters (injection flow rate, injection temperature, and lateral well spacing) are examined under different operational scenarios with other parameters. For example, injection flow rate in this study ranges from 20 1/s to $70 \mathrm{l} / \mathrm{s}$. Therefore, when examining the effect of the injection flow rate on production, different cases of injection temperature and well spacing are considered, because their impact can also affect reservoir productivity.

The model addresses the limitations of previous research, which ignored the influence of fractures, reservoir representation, open boundaries influence, and the inclusion of different operational schemes. The study estimates the consequence of individual parameters on others and their corresponding influences on the productivity of a geothermal reservoir. Solving the structure of this heterogeneous system, which is nonlinear in parameters and has a coupled interaction in nature, requires the use of a powerful numerical solver. The finite element method (FEM) is adopted here because of its robustness in dealing with such problems. The FEM package employed in the study is COMSOL with a link to MATLAB that serves as a framework for implementing the numerical model and making the required coupling between the physics [33]. At the end, numerical studies are carried out to verify the developed model, and sensitivity analyses are performed to investigate the influence of the parameters on reservoir productivity.

\section{Modelling thermo-hydraulic coupled problems}

The first step in the analysis of coupled fluid flow and heat transport problems consists of defining the geometry, material properties, initial and boundary conditions [34]. The geometry can be created or imported from a CAD program once it is developed by including the material properties and initial and boundary conditions. The next step is defining the mathematical model and coupled processes to be solved. The final two stages are independent of the type of 
numerical technique employed in solving the mathematical model except that the chosen solution procedures should be capable of solving the model accurately.

Modelling geothermal energy exploration and exploitation requires coupling the complex interaction occurring among different phenomena in the subsurface. These phenomena include fluid flow, heat transport, chemical transport and mechanical deformation. However, this study is limited to the coupled processes of heat transport and fluid flow in a fully saturated and fractured porous media. Figure 1 presents the two-way coupled approach used in this study, the illustration showed the hydraulic process is affected by temperature gradient directly through the change in density and viscosity of the fluid, and the thermal process, on the other hand, is influenced by the convective heat transfer through Darcy's velocity term. For further details on coupled processes in the field of geosciences see [35].

The macroscopic governing equations describing the behaviour of the fully coupled TH model demonstrated in the previous section compels the application of conservation laws of energy and mass. In this study, the derived equations are based on a dual porosity-permeability model (the model that accounts for rock matrix and fracture properties as a separate continuum). Therefore, this section will derive the partial differential equations for both the fluid flow and heat transport using the dual porosity-permeability approach are given here.

The law of conservation of mass governs the fluid flow expression in porous media, and the law states that the mass inflow subtracted by the mass outflow is equal to the total mass accumulated by a system. Thus, the conservation of mass fluid in porous matrix system is

$$
\frac{\partial}{\partial t}\left(\rho_{L} \phi\right)+\nabla \cdot\left(\rho_{L} v\right)=0
$$

where $\nabla$. is the divergence operator, $\rho_{L} v$ is the fluid mass flux and $\rho_{L} \phi$ is the mass per unit volume within the matrix. The term $\rho_{L}$ is the fluid density, $\phi$ is the matrix porosity and $v$ is the Darcy's flux or velocity, which is defined as

$$
v=\frac{\kappa}{\mu}\left(-\nabla P+\rho_{L} g \nabla z\right)
$$

where $\kappa$ is the intrinsic permeability of the matrix, $\mu$ is the dynamic viscosity, $P$ is the fluid pressure, $g$ is the acceleration due to gravity, and $z$ is the elevation. Substituting equations (2) into (1) and rearranging gives 


$$
\frac{\partial}{\partial t}\left(\phi \rho_{L}\right)+\nabla \cdot \rho_{L}\left[\frac{\kappa}{\mu}\left(-\nabla P+\rho_{L} g \nabla z\right)\right]=0
$$

196 Expanding the first term in the equation (3) by expressing the porosity and density as functions 197 of the fluid pressure, and applying the product rule and chain rule of differentiation yields

$$
\frac{\partial}{\partial t}\left(\phi \rho_{L}\right)=\phi \frac{\partial \rho_{L}}{\partial P} \frac{\partial P}{\partial t}+\rho_{L} \frac{\partial \phi}{\partial P} \frac{\partial P}{\partial t}
$$

Also, the equation of state (EOS) [36] defines the fluid and matrix compressibilities as

200

$$
C_{f}=\frac{1}{\rho_{L}} \frac{\partial \rho_{L}}{\partial P}, \text { and } C_{m}=\frac{1}{\phi} \frac{\partial \phi}{\partial P}
$$

201

202

203

204

205

206

207

208

209

210

211

212

where $C_{f}$ and $C_{m}$ are the fluid and matrix compressibility, respectively. Rearranging equations (5) and inserting the terms into equation (4) yields

$$
\frac{\partial}{\partial t}\left(\phi \rho_{L}\right)=\phi \rho_{L}\left(C_{f}+C_{m}\right) \frac{\partial P}{\partial t}
$$

where $\phi\left(C_{f}+C_{m}\right)$ is defined as linearised storage $S$, and equation (6) becomes

$$
\frac{\partial}{\partial t}\left(\phi \rho_{L}\right)=\rho_{L} S \frac{\partial P}{\partial t}
$$

The generalised equation applied for solving problems in porous matrix is obtained by substituting equation (7) into (3)

$$
\rho_{L} S \frac{\partial P}{\partial t}+\nabla \cdot \rho_{L}\left[\frac{\kappa}{\mu}\left(-\nabla P+\rho_{L} g \nabla z\right)\right]=0
$$

The subscript's $f$ and $m$ refer to fracture and matrix, respectively. The term $\rho_{L} \phi_{f}$ is mass per unit volume within the fracture, $\rho_{L} v_{f}$ is defined as the fluid mass flux within the fracture and $\phi_{f}$ is the fracture porosity. The term $Q_{f}$ denotes the flow from the matrix to the fracture which sometimes referred as the matrix-fracture transfer term. This term describes the flow in the 
fracture system contains a source term that represents the transport of fluid from the matrix to the fracture that is assumed to be distributed over the entire domain. Two different approaches can be used to determine the matrix-fracture transfer term $Q_{f}$, as described in [37-39]. However, in this study, the latter model [40] is chosen and is given as

$$
Q_{f}=-\sum \chi_{i}(x) \frac{1}{\left|\Omega_{i}\right|} \int_{\Omega_{i}} \frac{\partial\left(\phi \rho_{L}\right)}{\partial t} d x, \text { and } \chi_{i}(x)= \begin{cases}1 & \text { if } x \in \Omega_{i}, \\ 0 & \text { otherwise }\end{cases}
$$

where $\left|\Omega_{i}\right|$ represents the volume of the ith matrix block (i.e. $\left.\Omega_{i}\right)$ and $\chi_{i}(x)$ is its characteristic function. On the other hand, the term $Q_{m}$ is the external sources or sinks of fluid that may be comprised of an injection or production source and sometimes others sources/sinks from the surrounding boundaries. In this case, the expression of $Q_{m}$ is adopted from [41], by assuming that the sum of the normal components of fluid flow from the matrix block through the boundary cell, given here as

$$
Q_{m}=-\int_{\text {cellboundary }} \nabla \cdot \frac{\kappa \rho_{L}}{\mu} \nabla P \cdot \vec{n} d x
$$

The Darcy's flux or velocity of the fluid in an equivalent fracture system $v_{f}$, defined as

$$
v_{f}=\frac{\kappa_{f}}{\mu}\left(-\nabla P_{f}+\rho_{L} g \nabla z\right)
$$

in which the fracture permeability $\kappa_{f}$ is assumed to obey laminar flow by applying the concept of parallel plate and considering it as a uniform plate, expressed as

$$
\kappa_{f}=\frac{b^{2}}{12}
$$

where $b$ is the fracture aperture.

Substituting equation (13) into (12), and inserting output back into equation (9), and also replacing the first term in bracket of equation (9) by applying similar expression obtained in (7) gives the generalised expression (14) for solving fracture problems in porous media, namely

$$
\rho_{L} S_{f} \frac{\partial P_{f}}{\partial t}+\nabla \cdot \rho_{L}\left[\frac{b^{2}}{12 \mu}\left(-\nabla P_{f}+\rho_{L} g \nabla z\right)\right]+Q_{f}+Q_{m}=0
$$


240 However, it is critical to note that solving equations (8) and (14) requires boundary conditions,

which are $\rho_{L} v \cdot n$, and $\rho_{L} v_{f} \cdot n$ for the matrix and fracture, respectively. Explicit details are provided in section 3 under the finite element formulations.

In this paper, local thermal equilibrium heat transport equations between the solid and fluid phases is considered, in which the solid temperature $\left(T_{S}\right)$ is equal to the fluid temperature $\left(T_{f}\right.$ ) (i.e., $T_{S}=T_{f}=T$ ). Here, it is assumed that heat conduction in the solid and fluid phases occur side-by-side so that there is no net heat transport from one phase to the other. Therefore, the classical Newton's law of cooling is not applicable here, because it is very hard to estimate all the parameters included in the formula. However, it is only possible to apply the formula under laboratory conditions. The governing equation defining heat transport in porous media is the conservation of energy law expressed as

$$
\frac{\partial}{\partial t} A_{E}+\nabla \cdot q_{E}=0
$$

where $A_{E}$ is the energy per unit volume is given

$$
A_{E}=\phi_{S} \rho_{S} c_{\rho, S} T+\left(1-\phi_{S}\right) \rho_{L} c_{\rho, L} T=\rho c_{\rho} T
$$

in which $\phi_{s}$ and $\phi_{L}$ are the solid and liquid volume fraction (porosity), respectively; $c_{\rho, S}$ and $c_{\rho, L}$ are the specific heat capacity for the solid and liquid, respectively; $\rho_{S}$ is the density of the solid and $T$ is the temperature. Also, $q_{E}$ is the energy flux given by

$$
q_{E}=\rho_{L} v c_{\rho, L} T+q
$$

The coupled contribution of convective heat transfer is giving in the first term of the right-hand side of equation (16) while $q=-\lambda \nabla T$ is the input of conductive heat transfer referred as the Fourier's law, where $\lambda$ is the effective thermal conductivity of both the solid and liquid phases expressed as $\lambda=\phi_{S} \lambda_{S}+\left(1-\phi_{S}\right) \lambda_{L}$, in which $\lambda_{S}$ is the solid thermal conductivity and $\lambda_{L}$ is liquid thermal conductivity. Substituting equations (16) and (17) with their derivatives into equation (15) yields the general expression for solving heat transport in the porous matrix as, i.e.

$$
\rho c_{\rho} \frac{\partial T}{\partial t}+\nabla \cdot\left(\rho_{L} v c_{\rho, L} T-\lambda \nabla T\right)=0
$$

Similarly, the conservation of fracture energy within a matrix block is given by 


$$
\rho c_{\rho} \frac{\partial T}{\partial t}+\nabla \cdot\left(\rho_{L} v_{f} c_{\rho, L} T-\lambda_{f} \nabla T\right)+Q_{f, E}+Q_{m, E}=0
$$

where $Q_{f, E}$ and $Q_{m, E}$ are the energy sources/sinks for the fracture and matrix systems, $A_{f, E}$ is the energy per unit volume within the fracture expressed similarly to equation (17), $q_{f, E}$ is the

272 energy flux within the fracture. However, by putting into consideration it obeys the theory of parallel plate for fracture opening. Expanding and solving for the sub-equations within (19) as presented in the matrix section of the heat transport (equation (15-18)) on fractures, yields the general expression for heat transport in fractures given in equation (20).

\section{Finite element formulation for coupled TH model}

This section presents the application of finite element method (FEM) to coupled TH problems in fully saturated and fractured porous media. The use of the coupled procedures and the partial differential equations (PDE) displayed above is incorporated in developing the FEM model. It is essential to define the initial and boundary conditions (BC) of the problem before formulating the finite element solutions. The initial conditions specify the field pressures and temperatures at $t=0$, i.e.

$$
P=P_{0}, T=T_{0} \text { in } \Omega \text { and on } \Gamma
$$

where $\Omega$ is the domain of interest and $\Gamma$ is the boundary.

In the case of BC's, they can be defined in two different kind that include the Dirichlet $\mathrm{BC} \Gamma$ , and the Neumann BC $\Gamma^{q}$. For the fluid flow, the Dirichlet pressure BC can be imposed as a constant value either at the injection/extraction wellbore boundaries, or far-field boundaries as

$$
P=\hat{P} \text { on } \Gamma_{P}
$$

The Neumann BC for the fluid flow can be prescribed as a mass flux normal to the boundary surface or at the injection/extraction wellbore boundaries as

$$
q_{P}=\rho_{L} \frac{\kappa}{\mu}\left(-\nabla P+\rho_{L} g \nabla z\right)^{T} \cdot n \text { on } \Gamma_{P}^{q}
$$


where $n$ is normal to the boundary. Also, sometimes it can be employed as no-flow boundaries by setting equation (23) to zero.

In the case of heat transfer, the Dirichlet temperature BC can be imposed as a value (in the case of isothermal condition) at the injection wellbore boundary or far-field boundaries as

$$
T=\hat{T} \text { on } \Gamma_{T}
$$

The Neumann BC for the heat transfer can be imposed as a heat flux normal to a boundary or as an injection wellbore boundary (in the case of non-isothermal condition), which is given as

$$
q_{T}=\left(-\lambda \nabla T+\rho_{L} C_{P, L} v T\right)^{T} \cdot n \text { on } \Gamma_{T}^{q}
$$

In addition, the Neumann $\mathrm{BC}$ can also be prescribed as heat flux value at the heat outflow $\mathrm{BC}$ in the production wellbore boundary using the expression for the convective heat transfer as $q_{T}=\rho_{L} v \cdot n$.

The boundary value problem presented in the previous section, for example equations (8) is written as

$$
\begin{aligned}
& X(u)=B(u)+J=0 \text { in } \Omega \\
& Y(u)=D(u)+K=0 \text { on } \Gamma
\end{aligned}
$$

where $X$ and $Y$ are the derivate of differential operators, $B$ and $D$ are appropriate differential operators, and $J$ and $K$ are known functions independent of the field variable u, which are the exact solution of the boundary value problem. By considering the integral statement

$$
\int_{\Omega} \varphi^{T} X(u) d \Omega+\int_{\Gamma} \hat{\varphi}^{T} Y(u) d \Gamma=0
$$

is satisfied for a set of arbitrary functions $\varphi$ and $\hat{\varphi}$, which is equivalent to satisfying differential equation (26) and (27). If equations (26) and (27) are satisfied, then equation (28) is true. An approximate solution is sought in the class of functions $\hat{u}$, namely

$$
u \approx \hat{u}=\sum_{i}^{j} N_{i} a_{i}=N a
$$

which is obtained by introducing a set of trial or shape functions $N_{i}$ regarding the coordinates; and $a_{i}$ are the unknown values defined at points (nodes) in the domain $\Omega$ and the boundary $\Gamma$. If equation (29) is substituted into (26) and (27), they remain an error, or residual, i.e. 


$$
R=R_{\Omega}+R_{\Gamma}=X(\hat{u})+Y(\hat{u})
$$

322 To minimise the residual over the whole domain and the boundary, a zero value for an 323 appropriate number of integrals of the error over $\Omega$ and $\Gamma$, weighted by weighting functions $w$ and $\hat{w}$, is sought, which is called the weighted residual method (WRM) [42], namely

$$
\int_{\Omega} w^{T} X(\hat{u}) d \Omega+\int_{\Gamma} \hat{w}^{T} Y(\hat{u}) d \Gamma=0
$$

326

327

Expression (31) is an approximation to the integral defined in equation (28) and results in a set of equations for the unknowns $a_{i}$, which can be written as

$$
K a=f
$$

where $K$ is the stiffness matrix, $a$ is the unknown field; and $f$ is the load matrix defined as

$$
K_{i j}=\sum_{e=1}^{m} K_{i j}^{e} \quad f_{i}=\sum_{e=1}^{m} f_{i}^{e}
$$

where $K^{e}$ is known as the stiffness matrix for the $e^{\text {th }}$ element and $f^{e}$ is the boundary flux for the $e^{\text {th }}$ element, and the derivative of the differential operators $X$ and $Y$ must be continuous over the domain. The WRM, that is equation (31), is now applied to mass conservation equations (8) and its Neumann boundary condition equation (21), which yields

$$
\int_{\Omega} w^{T}\left\{\nabla^{T}\left[\frac{\kappa}{\mu}\left(-\nabla P+\rho_{L} g \nabla z\right)\right]\right\} d \Omega+\int_{\Omega} w^{T} S \frac{\partial P}{\partial t} d \Omega+\int_{\Gamma_{p}^{q}} \hat{w}^{T}\left[\frac{\kappa}{\mu}\left(-\nabla P+\rho_{L} g \nabla z\right)^{T} \cdot n-\frac{q_{p}}{\rho_{L}}\right] \cdot d \Gamma=0
$$

By limiting the choice of the weighting functions [42], such that

$$
\begin{array}{lll}
w=0 & \text { on } & \Gamma_{P} \\
\hat{w}=-w & \text { on } & \Gamma_{p}^{q}
\end{array}
$$

Applying the Green's theorem on the first portion of equation (34) and incorporating equations (35) and (36) into it, gives

$$
\int_{\Omega}\left[-(w \nabla)^{T}\left(-\frac{\kappa}{\mu} \nabla P+\frac{\kappa}{\mu} \rho_{L} g \nabla z\right)\right] d \Omega+\int_{\Omega} w^{T} S \frac{\partial P}{\partial t} d \Omega+\int_{\Gamma_{p}^{q}} w^{T} \frac{q_{p}}{\rho_{L}} d \Gamma=0
$$


343 The same procedure applied to the fluid flow when used in the energy balance equation in (18),

344

345

346

347

348

349

350

351

352

353

354

355

356

357

358

359

360

361

362

363

364

365

$$
\int_{\Omega} N_{T}^{T} c_{\rho} \rho N^{T} \frac{\partial \hat{T}}{\partial t} d \Omega+\int_{\Omega}\left[\left(N_{T}^{T} c_{\rho, L} q_{m} \cdot \nabla N_{T}\right) \hat{T}\right] d \Omega+\int_{\Omega} \nabla N_{T}^{T}\left(-\lambda \nabla N_{T}\right) \hat{T} d \Omega+\int_{\Gamma_{T}^{q}} N_{T}^{T} q^{T} d \Gamma=0
$$

also applying the Green's theorem to the second portion of equation (18), yields

$$
\int_{\Omega} w^{T} c_{\rho} \rho \frac{\partial T}{\partial t} d \Omega+\int_{\Omega} w \rho_{L} v c_{\rho, L} \cdot \nabla T d \Omega+\int_{\Omega}(\nabla w)^{T} \cdot(-\lambda \nabla T) d \Omega+\int_{\Gamma_{T}^{q}} w^{T} q^{T} d \Gamma=0
$$

Equations (37) and (40) are the weak formulation (weak form) of the governing equations presented in section 2.2, and by applying the Galerkin FEM to discretise the weak form spatially [43]. The state variables are expressed regarding the nodal values and shape functions as

$$
P=N_{P} \hat{P} ; T=N_{T} \hat{T}
$$

where $\hat{P}$ and $\hat{T}$ are the scalars of the nodal values of the pressures and temperature, $N_{P}$ and $N_{T}$ are shape functions. For a coarse tetrahedral element of $3 \mathrm{D}$ problem, they can be represented as

$$
N_{P}=\left[\begin{array}{llll}
N_{P 1} & N_{P 2} & N_{P 3} & N_{P 4}
\end{array}\right], N_{P i}=\text { diagonal }\left\{N_{P i} N_{P i} N_{P i} N_{P i}\right\}, i=1,4
$$

$$
N_{T}=\left[\begin{array}{llll}
N_{T 1} & N_{T 2} & N_{T 3} & N_{T 4}
\end{array}\right], N_{T i}=\text { diagonal }\left\{N_{T i} N_{T i} N_{T i} N_{T i}\right\}, i=1,4
$$

By the introduction of equation (41) into equations (37) and (40); then applying the Galerkin FEM, and replacing the weighting functions $w$ and $\hat{w}$ with the corresponding shape functions $N_{P}$ and $N_{T}$, gives

$$
\int_{\Omega}\left[\left(\nabla N_{P}\right)^{T} \frac{\kappa}{\mu} \nabla N_{P} \hat{P}-\left(\nabla N_{P}\right)^{T} \frac{\kappa}{\mu} \rho_{L} g \nabla z\right] d \Omega+\int_{\Omega} N_{P}^{T} S N_{P} \frac{\partial \hat{P}}{\partial t} d \Omega+\int_{\Gamma_{P}^{q}} N_{P}^{T} \frac{q_{p}}{\rho_{L}} d \Gamma=0
$$


85

Further discretising equations (44) and (45) gives

$$
\begin{gathered}
K_{P}=\int_{\Omega} N_{P}^{T} S N_{P} d \Omega \\
M_{P}(T)=\int_{\Omega}\left(\nabla N_{P}\right)^{T} \frac{\kappa}{\mu} \nabla N_{P} d \Omega \\
f^{P}(T)=\int_{\Omega}\left(\nabla N_{P}\right)^{T} \frac{\kappa}{\mu} \rho_{L} g d \Omega-\int_{\Gamma} N_{P}^{T} \frac{q_{p}}{\rho_{L}} d \Gamma \\
K_{T}=\int_{\Omega} N_{T}^{T} c_{\rho} \rho N_{T} d \Omega \\
M_{T}(P)=\int_{\Omega}\left\{N_{T}^{T}\left(\rho_{L} v c_{\rho, L} \cdot \nabla N_{T}\right)+\nabla N_{T}^{T}\left(-\lambda \nabla N_{T}\right)\right\} d \Omega \\
f^{T}(P)=-\int_{\Gamma_{T}^{q}} N_{T}^{T} q_{T} d \Gamma
\end{gathered}
$$

where $K_{P}$ is the compressibility matrix; $M_{p}$ is the permeability matrix; $f^{P}$ is the load matrix for the fluid flow process; $K_{T}$ is the capacity matrix; $M_{T}$ is the conductivity matrix; and $f^{T}$ is the load matrix for the heat transport. The staggered method is considered in coupling terms of the equations (44) and (45). By using equations (46) - (51), equations (44) and (45) are written as

$$
\begin{aligned}
& M_{p}(T) \hat{P}+K_{P} \frac{\partial \hat{P}}{\partial t}=f^{P}(T) \\
& M_{T}(P) \hat{T}+K_{T} \frac{\partial \hat{T}}{\partial t}=f^{T}(P)
\end{aligned}
$$

The above equations are represented in matrix form as

$$
\left[\begin{array}{cc}
M_{P}(T) & 0 \\
0 & M_{T}(P)
\end{array}\right]\left\{\begin{array}{l}
\hat{P} \\
\hat{T}
\end{array}\right\}+\left[\begin{array}{cc}
K_{P} & 0 \\
0 & K_{T}
\end{array}\right] \frac{\partial}{\partial t}\left\{\begin{array}{l}
\hat{P} \\
\hat{T}
\end{array}\right\}=\left\{\begin{array}{l}
f^{P}(T) \\
f^{T}(P)
\end{array}\right\}
$$

383 Similarly, by applying the procedure of FEM solution obtained in (52) and (53) to the fracture 384 equations in (14) and (20), yields

$$
M_{p, f}(T) \hat{P}_{f}+K_{P, f} \frac{\partial \hat{P}_{f}}{\partial t}=f^{P, f}(T)
$$




$$
M_{T, f}(P) \hat{T}_{f}+K_{T, f} \frac{\partial \hat{T}_{f}}{\partial t}=f^{T, f}(P)
$$

where $K_{P, f}$ is the compressibility matrix for the fracture; $M_{p, f}$ is the permeability matrix for the fracture; $f^{P, f}$ is the load matrix for the fracture flow; $K_{T, f}$ is the capacity matrix for the fracture; $M_{T, f}$ is the conductivity matrix for the fracture; and $f^{T, f}$ is the load matrix for the fracture heat transport.

\section{Solution procedure and verification}

In this study, the fluid flow and the heat transport field equations are considered as independent systems for the pressure, and thermal multi-coupling mathematical model. The staggered method equation is used with the Galerkin method (finite element discrete method) in the geometry domain to obtain the numerical solution of the coupling iteration problems. Then, by applying the finite difference method (FDM) in the time domain as discussed in [44], to obtain the solution of the coupled equations (52) and (53), by

$$
\begin{aligned}
& M_{p}(T)\left[P_{t+1}-P_{t}\right] / \Delta t+K_{P}\left[\theta P_{t+1}+(1-\theta) P_{t}\right]=f^{P}(T) \\
& M_{T}(P)\left[T_{t+1}-T_{t}\right] / \Delta t+K_{T}\left[\theta T_{t+1}+(1-\theta) T_{t}\right]=f^{T}(P)
\end{aligned}
$$

For the discrete fracture equations (55) and (56), the solution is obtained from

$$
\begin{aligned}
& \left.\left.M_{p, f}(T) \mid P_{f_{t+1}}-P_{f_{t}}\right\rfloor / \Delta t+K_{P, f} \mid \theta P_{f_{t+1}}+(1-\theta) P_{f_{t}}\right\rfloor=f^{P, f}(T) \\
& \left.\left.M_{T, f}(P) \mid T_{f_{t+1}}-T_{f_{t}}\right\rfloor / \Delta t+K_{T, f} \mid \theta T_{f_{t+1}}+(1-\theta) T_{f_{t}}\right\rfloor=f^{T, f}(P)
\end{aligned}
$$

where $t$ and $t+1$ indicates the previous and current time steps, respectively; $\Delta t$ is the time step size; $\theta$ is the relaxation parameter with limit $0 \leq \theta \leq 1$. The FDM is employed to calculate parameter by time step, and the specified initial time step with an acceleration factor of 1 . It is verified by repeated calculations to be stable and reliable for the computed results. The solution of the TH coupled nonlinear model is attained by using a mixture of Newton-Raphson and Picard schemes [45].

The convergence termination criterion employed for the nonlinear iterations in the study is the weighted Euclidean norm, which terminates the iteration solutions when the relative tolerance exceeds the relative error computed [46], given as 


$$
\text { Error }=\sqrt{\frac{1}{N_{F}}} \sqrt{\sum_{j=1}^{N_{F}} \frac{1}{N_{j}} \sum_{i=1}^{N_{j}}\left(\frac{\left|E_{i, j}\right|}{W_{i, j}}\right)^{2}}
$$

where $N_{F}$ is the number of fields and $N_{j}$ is the number of degrees of freedom in field $j$. The double subscript denotes the degree of freedom index $i$ and $j$ component. $E$ is the estimated error in the scalar, $W_{i, j}=\max \left(\left|U_{i, j}\right|, S_{j}\right), U_{i, j}$ is the current approximation to the solution scalar, and $S_{j}$ is a scale factor for which the program determines the scaling process.

To verify the solution capabilities described, a simple two-dimensional (2D) model is analysed by implementing the model in COMSOL with a link to MATLAB (COMMAT). The verification carried out here is the disturbance caused by the presence of fracture in a porous medium with a uniform flow. A similar problem was analysed by Strack as reported in [47], where an analytical model for this issue is derived as the potential flow. In this study, the model verified reported in [47] is used to verify the proposed model. Figure 2 presents the 2D model of the problem with a 1D fracture as a hydraulic conduit. Fluid is injected and extracted on the left $\mathrm{P}_{\text {in }}$ and right $\mathrm{P}_{\text {out }}$ sides of the model, respectively. On the other hand, the top and bottom represent no flow boundaries $\nabla \mathrm{P} \cdot n=0$. The fracture is $2 \mathrm{~m}$ in length with an orientation angle of $45^{\circ}$, and the flow is assumed to be laminar along its surface, and the shape is assumed to have normal displacements at the sides, as used in the case of a pressurised crack in an elastic medium, expressed as

$$
b=b_{\max } \sqrt{1-x^{\prime 2}}
$$

where $b_{\max }$ is the aperture at the centre and $x^{\prime}$ is the normalised local coordinate systems. Table $1[47]$ presents other parameters used in the numerical simulation of the porous media.

The results obtained are grouped into two sets. The first set of the results is the pressure distribution in the vicinity of the fracture and its flow pattern. Figure 3(a) presents the pressure distribution of the previously reported results [47], while Figure 3(b) depicts the numerical simulation carried out by the developed FE model. As observed, the results are in good agreement between the previous model and the FE model formulated in this work. The second set of the result verified in this study is the pressure profile along a diagonal line from the bottom-left passing through the fracture to the top-right of the geometry. Figure 4 presents the 
results of both the previous work and the current FE model. As can be seen, the graph shows a good agreement between the two solutions. Therefore, the capability of the newly developed FE model is verified using a related problem applicable to porous medium modelling.

\section{Geothermal reservoir case study}

448 Figure 5(a), shows a schematic representation of the reservoir geometry for Soultz geothermal system (i.e. half part of the reservoir), it depicts a deep geothermal system with $800 \mathrm{~m} \times 800$ $\mathrm{m} \times 5000 \mathrm{~m}$ deep. The reservoir is assumed to be $300 \mathrm{~m}$ in thickness and is located at about $4.5 \mathrm{~km}$ below the ground surface, and bounded at top and bottom by impermeable layers of granite. The top and bottom layers in Figure 5(a) represent the overburden and underburden, and the middle layer in-between display the reservoir. The wellbores constitute a doublet (single injector and producer) $11 \mathrm{~m}$ apart at the ground surface, and $600 \mathrm{~m}$ apart laterally at the reservoir level as given in the Soultz geothermal system. Also, the injection well is positioned $100 \mathrm{~m}$ and $400 \mathrm{~m}$ in the horizontal and vertical distances, while the production well is located $700 \mathrm{~m}$ and $400 \mathrm{~m}$ in both the $\mathrm{x}$ and $\mathrm{y}$ coordinates as shown in Figure 5(a). Both the injector and producer are inclined to angles of $10^{\circ}$ and $-10^{\circ}$, respectively.

Moreover, a single fracture intersects the reservoir through the overburden down to the underburden layer as in Figure 5(a). The fracture dips at an angle of $60^{\circ}$, which is a normal faulting regime to be precise with an approximated aperture of $50 \mathrm{~mm}$.

Table 2 presents the petro-physical properties and physical parameters used in the numerical model [4]. The material properties are extracted from the Soultz geothermal system as in [4]. For the fluid material properties, expressions presented by Holzbecher [48] are employed in the study, which includes density, viscosity, thermal conductivity, and heat capacity. Details of the properties can be found [48]. The system at initial pressure is hydrostatic throughout the model, and the initial temperature $\left(T_{\text {init }}\right)$ is given as $T_{\text {init }}=T_{\text {surf }}-0.03[\mathrm{~K} / \mathrm{m}] \times(-\mathrm{z})$, where $T_{\text {surf }}$ is surface temperature and is assumed to be 283.15 $\mathrm{K}$. The boundary condition applied for the temperature is $40^{\circ} \mathrm{C}$ (fluid injection temperature), and for the hydraulic process is $30 \mathrm{l} / \mathrm{s}$ (injection flow rate). Moreover, explicit details of the boundary conditions used in the geothermal reservoir model are provided in Table 3.

\subsection{Mesh and solution convergence}

474 In this model, the meshes are divided into three-dimensional (3-D) tetrahedral (for the matrix block), two-dimensional (2-D) triangular (for the fracture), and one-dimensional (1-D) line 
476 (wells) elements, respectively. Figure 5(b) showed the mesh system that connects finer and fine 477 grids in the calculation to reduce the impact of boundary effects. The implementation of the finer meshes on the wellbores is to increase the calculation accuracy; and also strengthens the calculating intensity and workload. Therefore, the mesh division method not only increases calculation accuracy but also eradicate the deviation caused by inappropriately selected boundary conditions, which have some significant effect on the long-term extracting vicinity and heat recovery after extraction.

The mesh convergence study of the proposed geothermal reservoir has been examined to explore the model computational efficiency in handling the cases of various structural variations mentioned. Five mesh sizes are utilised: M1=20463, M2=39925, M3=68780, M4=189774, and M5=747838 starting from coarse to extra fine. Figure 5(c) shows the results representing temperature profiles along the production wellbore for all meshes. It is also evident that there is no significant difference in the results between the five meshes, though the results of the coarse and normal meshes, M1 and M2, are less accurate. However, it manifests no numerical oscillations. Notwithstanding, it can be deduced that the model converged at M3 mesh. The CPU time for 55-time steps are M1=108 s, M2=201 s, M3=363 s, M4=1083 s, and M5=10177 s in an Intel(R) Core(TM) i5-5200U CPU@2.20 GHz, 2 cores.

To overcome numerical errors in the FEM solution, it is essential to check the convergence criterion for the solution. The convergence criterion in equation (58) is employed for the error estimation during solution iterations for the geothermal reservoir modelling. Figure 5(d) shows the number of iterations and the corresponding errors. The result indicates that an average of five iterations is sufficient to obtain an accurate solution.

\subsection{Effect of cold water front}

500 For the matrix block, the analysis is performed with an injection rate of $20 \mathrm{l} / \mathrm{s}$, an injection 501 temperature of $40^{\circ} \mathrm{C}$, and a well lateral distance of $600 \mathrm{~m}$. The temperature distribution study 502 confirms the activity of the coupled processes (between the thermal and hydraulic properties) 503 because the heat transfer mechanism is found to obey convective-dominated behaviour due to 504 the strong coupling. Figure 6(a) shows the temperature at time $t=0$, which happens to be same as the initial temperature of the system, affirming that the effect of the Dirichlet BC is yet to commence. However, there was a regional groundwater flow induced by the gradient from top to bottom existing before the injection. Figure 6(b) shows temperature distribution results after 15 years of simulation, with some part of the matrix experiencing the cooling effect of the 
injected fluid temperature. The process continues to propagate until the end of the simulation (30 years), as shown in Figure 6(c).

To investigate the effect of cold water front in the reservoir, the cold water, at a temperature of $40^{\circ} \mathrm{C}$, is injected at a rate of $201 / \mathrm{s}$ through two different injections well scenarios; one is situated $100 \mathrm{~m}$ and the other $50 \mathrm{~m}$ away from the left end. Hot water is extracted by two production wells; the first is located at $700 \mathrm{~m}$, and the second at $750 \mathrm{~m}$ from the left end, as shown in Figure 7(a-f). The effect of the cold water front propagation is examined after 1, 10 and 30 years of simulation for $600 \mathrm{~m}$ and $700 \mathrm{~m}$ lateral well spacing's as shown in Figures 7(af). In all the cases analysed, it was observed that the injected fluid creates a cold front near the injection well, which later evolves through the reservoir domain because the injected fluid is cooler than the geothermal reservoir.

Also, it should be noticed that the temperatures of the right boundaries are kept equal to the initial temperature of the reservoir until the cold-water front reaches the boundary, and after that, the temperature of the boundary starts increasing as presented in Figures 7(c-f).

\subsection{Parametric studies}

Developing a design model efficient in assessing the lifespan of a geothermal reservoir requires the understanding of some key control parameters during exploration and exploitation. In this study, three basic human control parameters are analysed by varying one parameter at a time using the OFAT approach, while keeping the rest at a constant based on the Soultz geothermal case, as presented in Section 5.1. The human control parameters studied here are injection flow rate (discharge), injection fluid temperature, and lateral well spacing. Studying these three key parameters provides a preliminary evaluation of the effects of reservoir parameters on the commercial applicability of enhanced geothermal system utilisation. The effects of the parameters are assessed based on the productivity of the reservoir during the exploitation period of 30 years. The geothermal reservoir conditions specified are simulated to acquire the anticipated variations in temperature, pressure, and thermal energy over 30 years. The parameters studied vary over the range of values that are acceptable for the geothermal exploitation of the Soultz site.

In a nutshell, the temperature of the reservoir was monitored using the parameters given above at production wellhead with a simulation period of 30 years.

\subsubsection{Effect of injection flow rate}


543 The injection flow rate is one of the human control parameters that have a direct effect on the 544 reservoir lifespan. In order to quantify the effect, six cases were analysed. These cases range 545 from 20 to 70 1/s with an incremental step of 10 1/s. Each of the cases is then studied under 546 different scenarios of injection temperature and well separation distances of $40^{\circ} \mathrm{C}$ and $50^{\circ} \mathrm{C}$, 547 and 600 and $700 \mathrm{~m}$, respectively. All other parameters remain constant as explained before. 548 Figure 8 shows the production wellbore temperature curves for the effect of various injection 549 flow rates. Figures $8(a)$ and 8 (b) present the temperature history at the production well for the scenarios of $40^{\circ} \mathrm{C}$ and $50^{\circ} \mathrm{C}$ under the effect of $600 \mathrm{~m}$ well distance, while Figures $8(\mathrm{c})$ and 8(d) show the production temperature for the same scenarios of injection temperature above with $700 \mathrm{~m}$ well spacing.

Figure $8 \mathrm{a}$ shows the temperature curves at the production wellbore for the different injection flow rates under a constant injection temperature of $40^{\circ} \mathrm{C}$ and lateral well spacing of $600 \mathrm{~m}$. As seen, the temperature curves differ for the various cases; the higher rate declines earlier than the lower rate. For example, the $70 \mathrm{l} / \mathrm{s}$ injection flow rate starts to decline just after 0.8 years of simulation, whereas the $20 \mathrm{l} / \mathrm{s}$ injection flow rate begins to decrease after approximately 2.6 years. As a result, the produced temperature is higher when the injection flow rate is lower, and vice versa. The reason for the variation is that the greater the injection flow rate, the faster the cooling of the reservoir is, and the lower the flow rate, the slower the cooling becomes. The same trend is observed in Figure $8 \mathrm{~b}$ when the injection fluid temperature is changed to $50^{\circ} \mathrm{C}$ in similar operational scenarios as in Figure $8 \mathrm{a}$, with slight shifts in the production temperature. It is noted that the increase in the injection fluid temperature to $50^{\circ} \mathrm{C}$ has a lesser effect on the produced temperature in those cases.

Figure $8 \mathrm{c}$ presents the temperature breakthrough curves at the production well for different injection flow rates under the influence of $40^{\circ} \mathrm{C}$ injection temperature and $700 \mathrm{~m}$ lateral well spacing. In these cases, the earliest decline starts after 1.6 years of simulation for the highest injection rate (i.e. $70 \mathrm{l} / \mathrm{s}$ ) and 5.6 years in the case of lowest injection flow rate (20 $1 / \mathrm{s})$. Furthermore, the decrease in the production temperature at the extraction well during the

57030 -year simulation is $8.31^{\circ} \mathrm{C}$ and $8.93^{\circ} \mathrm{C}$ for the lowest and highest injection flow rates, respectively. The low decline is recorded in these cases because the lateral well spacing between the injector and the producer is larger, so the production well bore is not affected much by the reservoir cooling after a 30-year simulation. Likewise, the same response is observed in

574 Figure 8d with slight changes in the production temperature due to the increase in the injection fluid temperature. 
In all the cases and scenarios, it is observed that as the injection rate increases, the reservoir temperature decreases rapidly. Moreover, the injection temperature and the well spacing also have some effects on the production rate. The maximum temperature is achieved when the injection temperature is at its lowest and well spacing is at its largest, then combined with the lower injection rate as shown in the figures presented.

\subsubsection{Effect of injection fluid temperature}

The surrounding rock supplies some amount of the heat enthalpy conducted in the reservoir; however, the injected fluid temperature governs the major heat enthalpy added into the reservoir due to the convective heat transfer. In this study, six cases of fluid injection temperature are investigated. These cases range from $10^{\circ} \mathrm{C}$ to $60^{\circ} \mathrm{C}$ with an incremental step of $10^{\circ} \mathrm{C}$, and each of the cases is additionally studied under varying scenarios of pumping rates of $20 \mathrm{l} / \mathrm{s}$ and $30 \mathrm{l} / \mathrm{s}$, and well lateral spacing of $600 \mathrm{~m}$ and $700 \mathrm{~m}$. Figure 9 shows the temperature production curves for the effect of injection fluid temperatures. Figures 9(a) and 9(b) present the produced temperature for the scenarios of $20 \mathrm{l} / \mathrm{s}$ and $30 \mathrm{l} / \mathrm{s}$ following the influence of 600 $\mathrm{m}$ well spacing. Figure 9a shows the breakthrough temperature curves at the production well; the temperature curves begin to decline after approximately 1.8 years of simulation with a temperature of $150.93^{\circ} \mathrm{C}$ in almost all cases. After approximately $10-12$ years of simulation, a little gap is observed between the different injection temperature scenarios, and it continues to widen till the 30 -year simulation period. The reason for these similarities in the production temperature breakthrough curves is that the effect of reservoir cooling started in approximately the same period in all cases. Similarly, Figure $9 \mathrm{~b}$ shows the production breakthrough curves for the different injection temperature scenarios when combined with $30 \mathrm{l} / \mathrm{s}$ injection flow rate and $600 \mathrm{~m}$ lateral well spacing. As can be seen, the production temperature trend is similar to Figure 9a with little difference; in this case, the decline started after approximately 1.2 years of simulation (earlier than the former scenario) with a temperature of $150.93^{\circ} \mathrm{C}$ in almost all cases. Also, in this scenario, some little deviations are seen from approximately 8.5-10 years, and these continue to grow until the end of the simulation. The idea behind the earlier variation between the different cases is the increase in the injection flow rate to $30 \mathrm{l} / \mathrm{s}$, which causes the fast cooling of the reservoir.

Similarly, Figures 9(c) and 9(d) show the production temperatures using the same injected rate with $700 \mathrm{~m}$ well spacing. Figure $9 \mathrm{c}$ shows the temperature curves at the production wellbore for different cases of the injection fluid temperature under the influences of $20 \mathrm{l} / \mathrm{s}$ injection flow rate and $700 \mathrm{~m}$ lateral well spacing. As seen, the temperature breakthrough 
curves have a similar trend except in the case of the $10^{\circ} \mathrm{C}$ injection fluid temperature rate. The production temperature began to decline after approximately 4.2 years of the simulation cases of $20^{\circ} \mathrm{C}$ to $60^{\circ} \mathrm{C}$, while in the case of the $10^{\circ} \mathrm{C}$ injection scenario, it began at approximately three years of simulation. The temperatures at the decline stages are $150.73^{\circ} \mathrm{C}$ and $150.74^{\circ} \mathrm{C}$, in both the former and the latter, respectively. As the simulation continues, the breakthrough curve for the $10^{\circ} \mathrm{C}$ injection cases shows a sudden transition change from lower to higher between 8.8 and 9.2 simulation period and maintains a regular pattern till the end of the simulation, whereas the other cases maintain the same decline pattern. The reason for the variation of the $10^{\circ} \mathrm{C}$ case with remaining scenarios is that after equilibrium is reached for cooling the higher injection rate propagates faster to the production wellbore than the former. Likewise, Figure $9 \mathrm{~d}$ shows similar breakthrough curves as in Figure $9 \mathrm{c}$ with little difference concerning the starting period of decline and the transition phases of the $10^{\circ} \mathrm{C}$ injection due to the increase in the injection flow rate. Apart from those points, all other trend remains the same. In all the scenarios studied, it is observed that there were no significant changes in the produced temperature from the reservoir.

\subsubsection{Effect of lateral well spacing}

To overcome the cold water effect and water losses that result from reduced productivity of reservoir wells, they must be placed at an optimum distance from each other. The choice of place will depend on the geological formation and production flow rates. Larger well spacing results in greater reservoir sizes and vice versa. However, with large spaces between wells, fluid losses are likely to be a significant problem, and with small spaces, the fluid losses are negligible. Therefore, the well spacing must be optimised to achieve the maximum possible reservoir size and production flow rate. In this work, six scenarios of well lateral spacing are examined. The spaces between the reservoir wells are chosen as 400, 500,600,650,700, and 750 metres long, respectively. Also, in each of the scenarios, different injection rates, of $20 \mathrm{l} / \mathrm{s}$ and $30 \mathrm{l} / \mathrm{s}$, and injection fluid temperatures, of $30^{\circ} \mathrm{C}$ and $40^{\circ} \mathrm{C}$, are analysed. Figure 10 presents the temperature curve at the production wellbore for the effect of lateral well spacing. Figures 10 (a) and 10 (b) show the produced temperature in the cases where $201 / \mathrm{s}$ were injected at $30^{\circ} \mathrm{C}$ and $40^{\circ} \mathrm{C}$, respectively while Figures 10 (c) and $10(\mathrm{~d})$ show the production temperature when $30 \mathrm{l} / \mathrm{s}$ were injected at $30^{\circ} \mathrm{C}$ and $40^{\circ} \mathrm{C}$ respectively.

Figure 10a shows the temperature breakthrough curve at the extraction well for the different scenarios of the lateral well spacing when combined with an injection fluid temperature of $30^{\circ} \mathrm{C}$ and injection flow rate of $20 \mathrm{l} / \mathrm{s}$. As can be seen, the further the spacing, 
the higher the produced temperature, and vice versa. For instance, in the case of $400 \mathrm{~m}$ lateral well spacing, the temperature begins to decrease just after 0.8 years of the simulation period. Concerning the $700 \mathrm{~m}$ lateral wellbore spacing, the decline starts after approximately 9.4 years. Moreover, after a simulation period of 30 years, the produced temperature for the closer well spacing (i.e., $400 \mathrm{~m}$ ) was approximately $116^{\circ} \mathrm{C}$, and the largest spacing $(750 \mathrm{~m})$ is $145^{\circ} \mathrm{C}$, which amounted to a $30^{\circ} \mathrm{C}$ temperature difference between the two cases. The reason for this significant deviation between the scenarios is the closer the spacing, the higher the impact of cold water propagation on the production wellbore, and vice versa. Likewise, a similar trend of Figure 10a is seen in Figures 10b-d, with slight sights in the temperature breakthrough curves due to the different injection fluid temperatures and flow rates employed.

In all the scenarios, it is observed that as the lateral well spacing increases, the production temperature rises.

\subsection{Energy extraction rates}

The model adopted in this investigation is the one proposed by Kruger [49][50] for the calculations of the total energy extraction in all the scenarios and cases, expressed here as

$$
\Delta E_{i}=Q_{i} C_{\rho, L} \Delta T_{i}
$$

where $\Delta E_{i}$ is the annual energy produced in the $i^{\text {th }}$ year, $Q_{i}$ is the total production flowrate in the $i^{\text {th }}$ year, $C_{\rho, L}$ is the specific heat capacity of the circulated fluid, and $\Delta T_{i}$ is the temperature difference between the extracted and injected fluid in the $i^{\text {th }}$ year. The total energy produced from the system for 30 years of extraction can be written as

$$
\Delta E=\sum_{i=1}^{30} \Delta E_{i}
$$

Based on the limitations of the injection flow rate range and other parameter combinations studied in this work using the OFAT approach, the results show that as the injection flow rate increases, the energy extraction rate increases with a positive linear relationship as indicated in Figure 11, which shows that the injection rate increase affects the production output. Figure 11 also shows the influence of well spacing and the effect of injection fluid temperature on the energy extraction rate when combined with injection scenarios. The results revealed that wider 
well spacing coupled with lower fluid injection temperatures yields higher energy when compared to larger spacing with higher rates.

As for the effect of fluid injection temperature on the energy extraction rate, Figure 12 shows an inverse relationship between fluid injection temperature and the energy extraction rate. As the fluid injection temperature rises, the energy extracted from the reservoir declines significantly, because $\Delta T_{i}$ reduces with the rising fluid injection temperature. Hence, the reservoir lifespan is prolonged for the reproduction of hot water with the same temperature. Also, these cases are further investigated with different well spacing and fluid injection rates, and the results showed that larger well spacing linked with a higher injection fluid rate generates greater extraction energy in comparison to other combinations.

Figure 13 presents the effect of well spacing on the extraction energy of the reservoir. In all the scenarios analysed, it is observed that, as the well spacing increased, the energy extracted from the system increases rapidly due to the cold water front propagation affecting the closer wells earlier than the further ones. The increase shown in Figure 13 occurs in a nonlinear manner with two different gradients; the gradient of the first two spacing is steeper than the remaining ones because the latter spacing have similar resistance to the cold water front.

\section{Conclusions}

In this paper, a three-dimensional numerical model for coupled thermo-hydraulic processes in a heterogeneous fractured geothermal reservoir overlain and underlain by impermeable layers is proposed. The primary objective is to examine the effect of human control parameters on geothermal reservoir productivity. A verification study is first performed to test the capability of the solver, and the outcomes achieved are in agreement with the existing solvers. Also presented in the studies is the effect of cold water in the matrix block and reservoirs before conducting the main analyses on the human control parameters. An extensive parametric analysis is investigated for a broad range of the parameters and operational scenarios. The injection flow rate has a significant effect on energy production as the rate increases, the energy extraction rate rises, and the system lifetime decreases. Thus, higher injection flow rate is a positive factor in production and, at the same time, a negative factor on reservoir lifespan. In the case of fluid injection temperature, the effect is less significant to production because, as the injection temperature increases, the extraction energy declines rapidly and the reservoir 
lifespan increases. The well lateral spacing also behaves similarly to the injection flow rate, but it is not as effective as the injection flow rate regarding energy extraction and provides a longer reservoir lifetime than the former.

The developed model gives in-depth insight to stakeholders and reservoir engineers with regard to the key parameters to control during exploration and exploitation. The results presented can be effectively employed in the design of human control parameters in a geothermal reservoir system. The model can also serve as a reference solution to other complex interactions encountered in reservoir simulations.

\section{Acknowledgement}

The first author delightedly acknowledges the $\mathrm{PhD}$ scholarship funding support received from both the University of Greenwich (UK) and the Petroleum Technology Development Fund (PTDF) (Nigeria).

\section{References}

[1] A. H. D. Cheng, A. Ghassemi, and E. Detournay, "Integral equation solution of heat extraction from a fracture in hot dry rock," Int. J. Numer. Anal. Methods Geomech., vol. 25 , no. 13, pp. 1327-1338, 2001.

[2] A. Ghassemi, S. Tarasovs, and A. H.-D. Cheng, "A 3-D study of the effects of thermomechanical loads on fracture slip in enhanced geothermal reservoirs," Int. J. Rock Mech. Min. Sci., vol. 44, no. 8, pp. 1132-1148, Dec. 2007.

[3] O. Kolditz, "Modelling flow and heat transfer in fractured rocks: Conceptual model of a 3-D deterministic fracture network," Geothermics, vol. 24, no. 3, pp. 451-470, Jun. 1995.

[4] M. D. Aliyu and H. Chen, "Numerical Modelling of Coupled Hydro-Thermal Processes of the Soultz Heterogeneous Geothermal System," in ECCOMAS Congress 2016 VII European Congress on Computational Methods in Applied Sciences and Engineering M. Papadrakakis, V. Papadopoulos, G. Stefanou, V. Plevris (eds.) Crete Island, Greece, 5-10 June 2016, 2016, no. Volume I, pp. 1659-1671.

[5] J. Willis-Richards and T. Wallroth, "Approaches to the modelling of hdr reservoirs: A review," Geothermics, vol. 24, no. 3, pp. 307-332, Jun. 1995.

[6] A. E. Croucher and M. J. O'Sullivan, "Application of the computer code TOUGH2 to the simulation of supercritical conditions in geothermal systems," Geothermics, vol. 37, no. 6, pp. 622-634, 2008. 
[7] M. J. O’Sullivan, K. Pruess, and M. J. Lippmann, "State of the art of geothermal reservoir simulation," Geothermics, vol. 30, no. 4, pp. 395-429, Aug. 2001.

[8] M. J. O'Sullivan, A. Yeh, and W. I. Mannington, “A history of numerical modelling of the Wairakei geothermal field," Geothermics, vol. 38, no. 1, pp. 155-168, Mar. 2009.

[9] M. J. O’Sullivan, K. Pruess, and M. J. Lippmann, “Geothermal Reservoir Simulation : the State-of-Practice and Emerging Trends," in World Geothermal Congress 2000, Kyushu - Tohoku, Japan, May 28 - June 10, 2000, 2000, pp. 4065-4070.

[10] H. Xing, Y. Liu, J. Gao, and S. Chen, "Recent development in numerical simulation of enhanced geothermal reservoirs," J. Earth Sci., vol. 26, no. 1, pp. 28-36, 2015.

[11] Z. Y. Wong, R. Horne, and D. Voskov, "Comparison of Nonlinear Formulations for Geothermal Reservoir Simulations," in 41st Workshop on Geothermal Reservoir Engineering, Stanford, 2016, no. 2011, pp. 1-16.

[12] Y. Xia, M. Plummer, R. Podgorney, and A. Ghassemi, "An Assessment of Some Design Constraints on Heat Production of a 3D Conceptual EGS Model Using an Open-Source Geothermal Reservoir Simulation Code," in Stanford Geothermal Workshop, 2016, pp. 1-24.

[13] M. G. Blöcher, G. Zimmermann, I. Moeck, W. Brandt, A. Hassanzadegan, and F. Magri, “3D numerical modeling of hydrothermal processes during the lifetime of a deep geothermal reservoir," Geofluids, vol. 10, no. 3, pp. 406-421, 2010.

[14] T. Fischer, D. Naumov, S. Sattler, O. Kolditz, and M. Walther, "GO2OGS 1.0: A versatile workflow to integrate complex geological information with fault data into numerical simulation models," Geosci. Model Dev., vol. 8, no. 11, pp. 3681-3694, 2015.

[15] E. Wall, "United States Geothermal Support and the International Partnership for Geothermal Technology," in World Geothermal Congress 2010 Bali, Indonesia, 25-29 April 2010, 2010, no. April, pp. 1-4.

[16] S. K. White, S. Purohit, and L. Boyd, "Using GTO-Velo to Facilitate Communication and Sharing of Simulation Results in Support of the Geothermal Technologies Office Code Comparison Study," in Fourtieth Workshop on Geothermal Reservoir Engineering, 2015, pp. 1-10.

[17] M. D. White and B. R. Phillips, "Code Comparison Study Fosters Confidence in the Numerical Simulation of Enhanced Geothermal Systems," in 40th Stanford Geothermal Workshop, 2015, pp. 1-12.

[18] A. Ghassemi, S. Kelkar, and M. McClure, "Influence of Fracture Shearing on Fluid 
Flow and Thermal Behavior of an EGS Reservoir - Geothermal Code Comparison Study," in Fourtieth Workshop on Geothermal Reservoir Engineering, 2015, pp. 1-14.

[19] J. Burnell, M. O. Sullivan, J. O. Sullivan, W. Kissling, A. Croucher, J. Pogacnik, G. Caldwell, S. Ellis, S. Zarrouk, and M. Climo, "Geothermal Supermodels : the Next Generation of Integrated Geophysical , Chemical and Flow Simulation Modelling Tools," in Proceedings World Geothermal Congress 2015 Melbourne, Australia, 1925 April 2015, 2015, no. April, pp. 19-25.

[20] T. H. Fairs, P. L. Younger, and G. Parkin, "Parsimonious numerical modelling of deep geothermal reservoirs," in Proceedings of the Institution of Civil Engineers, Energy, 2015, pp. 1-11.

[21] M. Shook, "Parametric Study o f Reservoir Properties and Their Effect on Energy Recovery The Effect of Reservoir Structure," in Geothermal Reservoir Engineering Stanford University, 1992, pp. 63-71.

[22] G. Nalla, G. M. Shook, G. L. Mines, and K. K. Bloomfield, "Parametric sensitivity study of operating and design variables in wellbore heat exchangers," Geothermics, vol. 34, no. 3, pp. 330-346, 2005.

[23] A. Vecchiarelli, R. Sousa, and H. H. Einstein, "PARAMETRIC STUDY WITH GEOFRAC: A THREE-DIMENSIONAL STOCHASTIC FRACTURE FLOW MODEL," in Thirty-Eighth Workshop on Geothermal Reservoir Engineering Stanford University, Stanford, California, February 11-13, 2013 SGP-TR-198, 2013, no. 1992, pp. 1-9.

[24] J. Chen and F. Jiang, "Designing multi-well layout for enhanced geothermal system to better exploit hot dry rock geothermal energy," Renew. Energy, vol. 74, pp. 37-48, 2015.

[25] C. Jain, C. Vogt, and C. Clauser, "Maximum potential for geothermal power in Germany based on engineered geothermal systems," Geotherm. Energy, vol. 3, no. 1, p. 15, 2015.

[26] S. E. Poulsen, N. Balling, and S. B. Nielsen, "A parametric study of the thermal recharge of low enthalpy geothermal reservoirs," Geothermics, vol. 53, pp. 464-478, 2015 .

[27] M. D. Aliyu, H. Chen, and O. Harireche, "Finite element modelling for productivity of geothermal reservoirs via extraction well," in Proceedings of the 24th UK Conference of the Association for Computational Mechanics in Engineering 31 March-01 April 2016, Cardiff University, Cardiff, 2016, no. April, pp. 331-334. 
[28] G. B. Madhur and J. B. Anderson, "Sensitivity Analysis of Low-Temperature Geothermal Reservoirs: Effect of Reservoir Parameters on the Direct Use of Geothermal Energy,” GRC Trans., vol. 36, no. 10, pp. 1255-1262, 2012.

[29] S. Saeid, R. Al-Khoury, H. M. Nick, and M. A. Hicks, "A prototype design model for deep low-enthalpy hydrothermal systems," Renew. Energy, vol. 77, pp. 408-422, 2015.

[30] R. Hebert and B. Ledesert, "Calcimetry at soultz-sous-forêts enhanced geothermal system: relationships with fracture zones, flow pathways and reservoir chemical stimulation results," in In "Geothermal Energy, Technology and Geology”, Edited by Jianwen Yang, Nova Science Publishers Inc., NY, Chapter 3, no. September 2016, J. Yang, Ed. Nova Science Publishers, Inc., 2012, pp. 93-113.

[31] R. L. Hébert, B. Ledésert, D. Bartier, C. Dezayes, A. Genter, and C. Grall, “The Enhanced Geothermal System of Soultz-sous-Forêts: A study of the relationships between fracture zones and calcite content," J. Volcanol. Geotherm. Res., vol. 196, no. 1-2, pp. 126-133, Sep. 2010.

[32] D. W. Brown, "Hot dry rock geothermal energy: important lessons from Fenton Hill," in Thirty-Fourth Workshop on Geothermal Reservoir Engineering, 2009, pp. 3-6.

[33] M. D. Aliyu and H.-P. Chen, "Sensitivity analysis of deep geothermal reservoir: Effect of reservoir parameters on production temperature," Energy, vol. 129, pp. 101-113, Jun. 2017.

[34] K. J. Bathe, H. Zhang, and M. H. Wang, "Finite element analysis of incompressible and compressible fluid flows with free surfaces and structural interactions," Comput. Struct., vol. 56, no. 2-3, pp. 193-213, Jul. 1995.

[35] C.-F. Tsang, "Linking Thermal, Hydrological, and Mechanical Processes in Fractured Rocks,” Annu. Rev. Earth Planet. Sci., vol. 27, no. 1, pp. 359-384, May 1999.

[36] R. W. Zimmerman, "Coupling in poroelasticity and thermoelasticity,” Int. J. Rock Mech. Min. Sci., vol. 37, no. 1-2, pp. 79-87, 2000.

[37] Z. Chen, G. Huan, and Y. Ma, Computational Methods for Multiphase Flows in Porous Media, 1st ed. Philadelphia: Society for Industrial and Applied Mathematics, 2006.

[38] J. Warren and P. J. Root, "The behavior of naturally fractured reservoirs," SPE J., vol. 3, no. 3, pp. 245-255, 1963.

[39] G. . Barenblatt, I. . Zheltov, and I. . Kochina, "Basic concepts in the theory of seepage of homogeneous liquids in fissured rocks [strata]," J. Appl. Math. Mech., vol. 24, no. 5, 
pp. 1286-1303, Jan. 1960.

[40] T. Arbogast, J. Douglas, Jr., and U. Hornung, "Derivation of the Double Porosity Model of Single Phase Flow via Homogenization Theory,” SIAM J. Math. Anal., vol. 21, no. 4, pp. 823-836, 1990.

[41] K. M. Bower and G. Zyvoloski, “A numerical model for thermo-hydro-mechanical coupling in fractured rock," Int. J. Rock Mech. Min. Sci., vol. 34, no. 8, pp. 12011211, Dec. 1997.

[42] R. W. Lewis, P. Nithiarasu, and K. N. Seetharamu, Fundamentals of the Finite Element Method for Heat and Fluid Flow. Chichester, UK: John Wiley \& Sons, Ltd, 2005.

[43] H. Fan and S. Li, "A three-dimensional surface stress tensor formulation for simulation of adhesive contact in finite deformation," Int. J. Numer. Methods Eng., vol. 107, no. 3, pp. 252-270, Jul. 2016.

[44] M. Ferronato, N. Castelletto, and G. Gambolati, "A fully coupled 3-D mixed finite element model of Biot consolidation," J. Comput. Phys., vol. 229, no. 12, pp. 4813 $4830,2010$.

[45] F. Auricchio, A. Lefieux, A. Reali, and A. Veneziani, “A locally anisotropic fluidstructure interaction remeshing strategy for thin structures with application to a hinged rigid leaflet," Int. J. Numer. Methods Eng., vol. 107, no. 2, pp. 155-180, Jul. 2016.

[46] COMSOL, “COMSOL Reference Manual,” CM020005, 2015.

[47] O. Kolditz, U.-J. Görke, H. Shao, and W. Wang, Thermo-Hydro-Mechanical-Chemical Processes in Porous Media: Benchmarks and Examples, vol. 86. Berlin, Heidelberg: Springer Berlin Heidelberg, 2012.

[48] E. O. Holzbecher, Modeling Density-Driven Flow in Porous Media. Berlin, Heidelberg: Springer Berlin Heidelberg, 1998.

[49] P. Kruger, "HEAT EXTRACTION FROM HDR GEOTHERMAL RESERVOIRS," in World Geothermal Congress, 1995: Florence, Italy, 18-31 May 1995, 1995, no. C, pp. $2517-2520$.

[50] Y. Xia, M. Plummer, E. Mattson, R. Podgorney, and A. Ghassemi, "Design, modeling, and evaluation of a doublet heat extraction model in enhanced geothermal systems," Renew. Energy, vol. 105, pp. 232-247, 2017. 
Table 1: Model parameters adopted in model verification [42]

\begin{tabular}{llll}
\hline Parameters & Symbol & Value & Unit \\
\hline Porosity & $\phi$ & 1 & $\%$ \\
Hydraulic conductivity & $K$ & $1 \mathrm{e}-5$ & $\mathrm{~m} / \mathrm{s}$ \\
Fracture hydraulic conductivity & $K_{f}$ & $1 \mathrm{e}-3$ & $\mathrm{~m} / \mathrm{s}$ \\
Specific storage & $S$ & $1 \mathrm{e}-4$ & $\mathrm{~m} / \mathrm{s}$ \\
Injection pressure & $P_{\text {in }}$ & $4.965 \mathrm{e}+5$ & $\mathrm{~Pa}$ \\
Extraction pressure & $P_{\text {out }}$ & $-4.965 \mathrm{e}+5$ & $\mathrm{~Pa}$ \\
Density & $\rho$ & 1,000 & $\mathrm{~kg} / \mathrm{m}^{3}$ \\
Viscosity & $\mu$ & 0.001 & $\mathrm{~Pa} . \mathrm{s}$ \\
\hline
\end{tabular}


Table 2: Geological and petro-physical properties of the system [4]

\begin{tabular}{|c|c|c|c|}
\hline Parameter & Symbol & Value & Unit \\
\hline \multicolumn{4}{|l|}{ Overburden Layer } \\
\hline Thermal conductivity & $\lambda_{s}$ & 2 & $\mathrm{~W} / \mathrm{m} / \mathrm{K}$ \\
\hline Density & $\rho_{s}$ & 2500 & $\mathrm{Kg} / \mathrm{m}^{3}$ \\
\hline Heat capacity & $C_{\rho, S}$ & 900 & $\mathrm{~J} / \mathrm{kg} / \mathrm{K}$ \\
\hline Porosity & $\phi$ & 0.1 & 1 \\
\hline Permeability & $\kappa$ & $1 \mathrm{e}-18$ & $\mathrm{~m}^{2}$ \\
\hline \multicolumn{4}{|l|}{ Reservoir } \\
\hline Thermal conductivity & $\lambda_{s}$ & 3 & $\mathrm{~W} / \mathrm{m} / \mathrm{K}$ \\
\hline Density & $\rho_{s}$ & 2650 & $\mathrm{Kg} / \mathrm{m}^{3}$ \\
\hline Heat capacity & $C_{\rho, S}$ & 850 & $\mathrm{~J} / \mathrm{kg} / \mathrm{K}$ \\
\hline Porosity & $\phi$ & 0.3 & 1 \\
\hline Permeability & $\kappa$ & $1 \mathrm{e}-16$ & $\mathrm{~m}^{2}$ \\
\hline \multicolumn{4}{|l|}{ Underburden Layer } \\
\hline Thermal conductivity & $\lambda_{s}$ & 3.5 & $\mathrm{~W} / \mathrm{m} / \mathrm{K}$ \\
\hline Density & $\rho_{s}$ & 2700 & $\mathrm{Kg} / \mathrm{m}^{3}$ \\
\hline Heat capacity & $C_{\rho, S}$ & 850 & $\mathrm{~J} / \mathrm{kg} / \mathrm{K}$ \\
\hline Porosity & $\phi$ & 0.3 & 1 \\
\hline Permeability & $\kappa$ & $1 \mathrm{e}-18$ & $\mathrm{~m}^{2}$ \\
\hline \multicolumn{4}{|l|}{ Fracture } \\
\hline Thermal conductivity & $\lambda_{f, s}$ & 3.5 & $\mathrm{~W} / \mathrm{m} / \mathrm{K}$ \\
\hline Density & $\rho_{f, s}$ & 1200 & $\mathrm{Kg} / \mathrm{m}^{3}$ \\
\hline Heat capacity & $C_{\rho, S}$ & 800 & $\mathrm{~J} / \mathrm{kg} / \mathrm{K}$ \\
\hline Porosity & $\phi_{f}$ & 0.01 & 1 \\
\hline Permeability & $\kappa_{f}$ & $1 \mathrm{e}-12$ & $\mathrm{~m}^{2}$ \\
\hline
\end{tabular}

885

886

887 
Table 3: The boundary conditions employed in the geothermal reservoir model

\begin{tabular}{|c|c|c|}
\hline Physics & Boundary reference & Boundary condition \\
\hline \multirow[t]{5}{*}{ Hydraulic } & $\begin{array}{l}\text { Injection wellbore (i.e. injection flow } \\
\text { rate) }\end{array}$ & $\begin{array}{l}Q(t)_{\text {injection }}=30 \mathrm{l} / \mathrm{s} \\
0 \leq t \leq 30\end{array}$ \\
\hline & $\begin{array}{l}\text { Production wellbore (i.e. production } \\
\text { flow rate) }\end{array}$ & $\begin{array}{l}Q(t)_{\text {production }}=-30 \mathrm{l} / \mathrm{s} \\
0 \leq t \leq 30\end{array}$ \\
\hline & $\begin{array}{l}\text { Surfaces (top \& bottom) except at the } \\
\text { injection and production areas. }\end{array}$ & $\begin{array}{l}Q(t)=0 \\
0 \leq t \leq 30\end{array}$ \\
\hline & Surfaces (front, back, left, and right). & $P(t)=\rho_{L} g\left(H_{0}-D\right), \quad$ i.e., $\quad-\partial H \times x$ \\
\hline & & $0 \leq t \leq 30$ \\
\hline \multirow[t]{4}{*}{ Thermal } & $\begin{array}{l}\text { Injection wellbore (i.e. injection } \\
\text { temperature) }\end{array}$ & $\begin{array}{l}T(t)_{\text {injection }}=40^{\circ} \mathrm{C} \\
0 \leq t \leq 30\end{array}$ \\
\hline & $\begin{array}{l}\text { Production wellbore (i.e. unknown } \\
\text { temperature to be calculated) }\end{array}$ & $\begin{array}{l}T(t)_{\text {production }}=? \\
0 \leq t \leq 30\end{array}$ \\
\hline & $\begin{array}{l}\text { Surfaces (top \& bottom) except at the } \\
\text { injection and production areas. In this } \\
\text { case, the boundaries are thermal } \\
\text { insulated. }\end{array}$ & $\begin{array}{c}-n \cdot q(t)=0 \\
0 \leq t \leq 30\end{array}$ \\
\hline & Surfaces (front, back, left, and right). & $\begin{array}{l}T(t)=T_{\text {init }}(t) \text { if } n \cdot v<0 \\
-n \cdot q(t)=0, \text { if } n \cdot v \geq 0 \\
0 \leq t \leq 30\end{array}$ \\
\hline
\end{tabular}


896

897

898

899

900

901

902

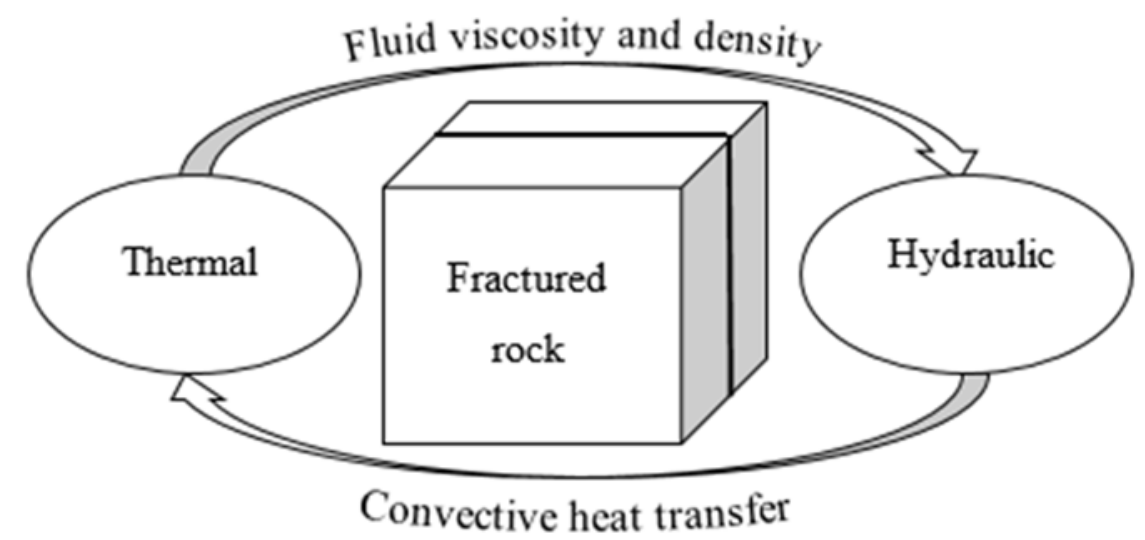

Figure 1: Two-way fully coupled Thermo-Hydro model

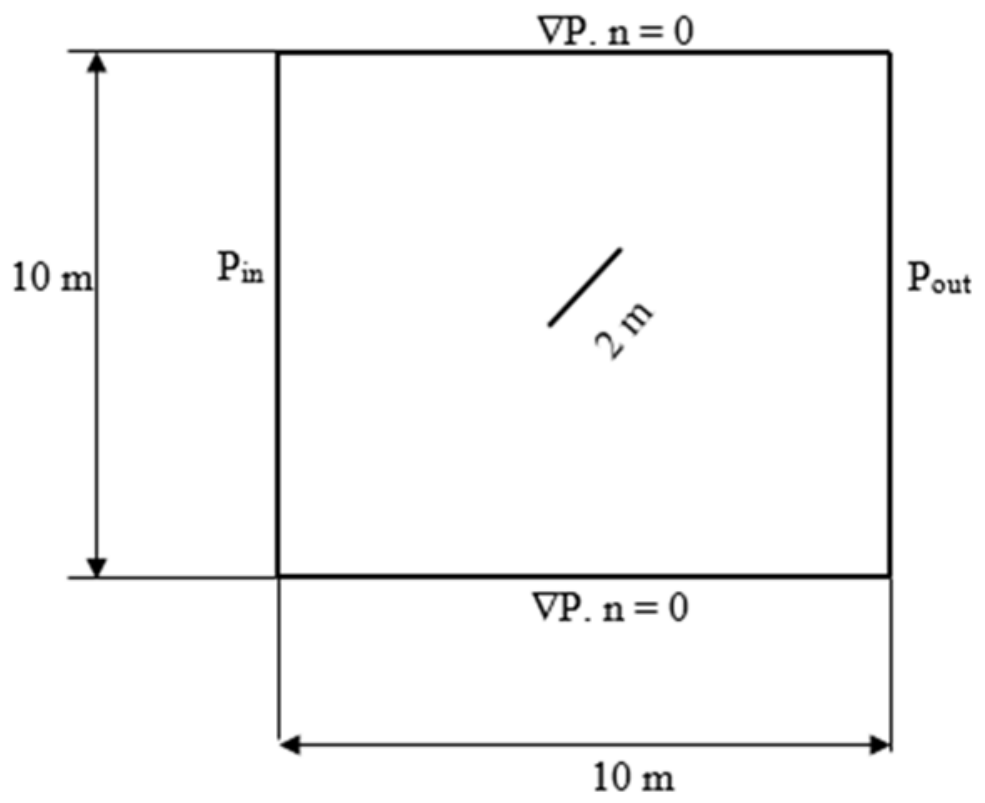

Figure 2: Model set-up (After [42] ) 

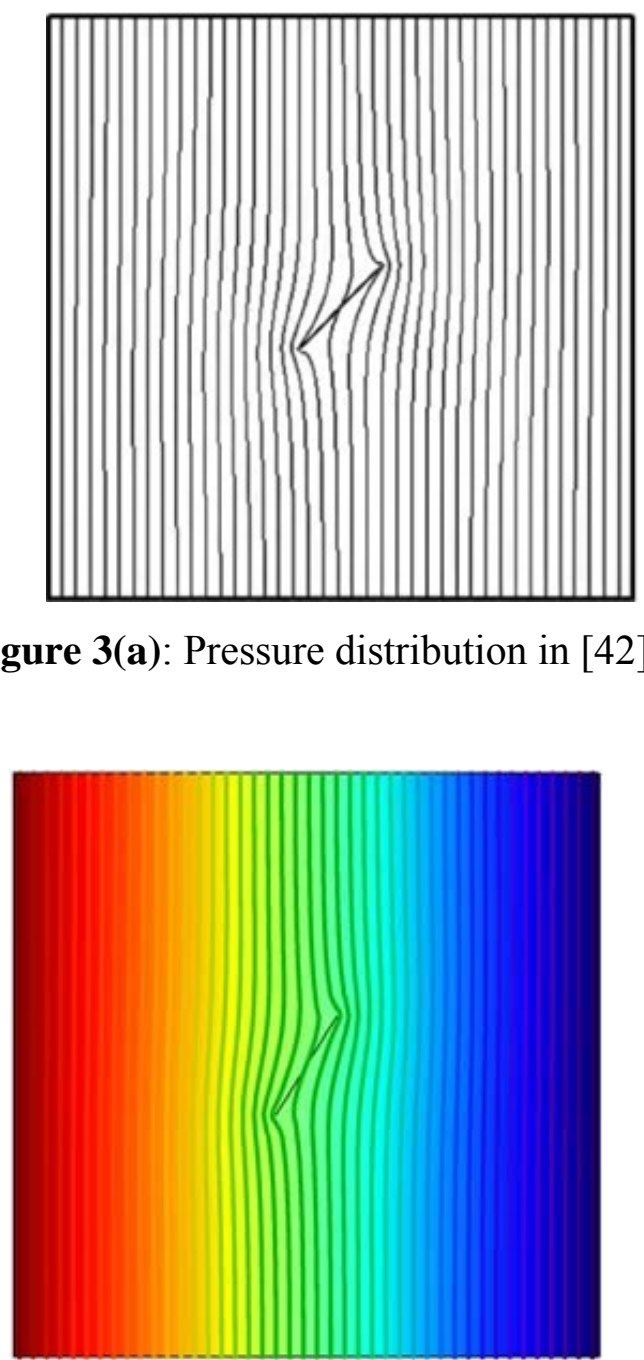

Figure 3(b): Pressure distribution for the current FE model

Figure 3: Verification of the proposed procedure with the existing model in [42] 


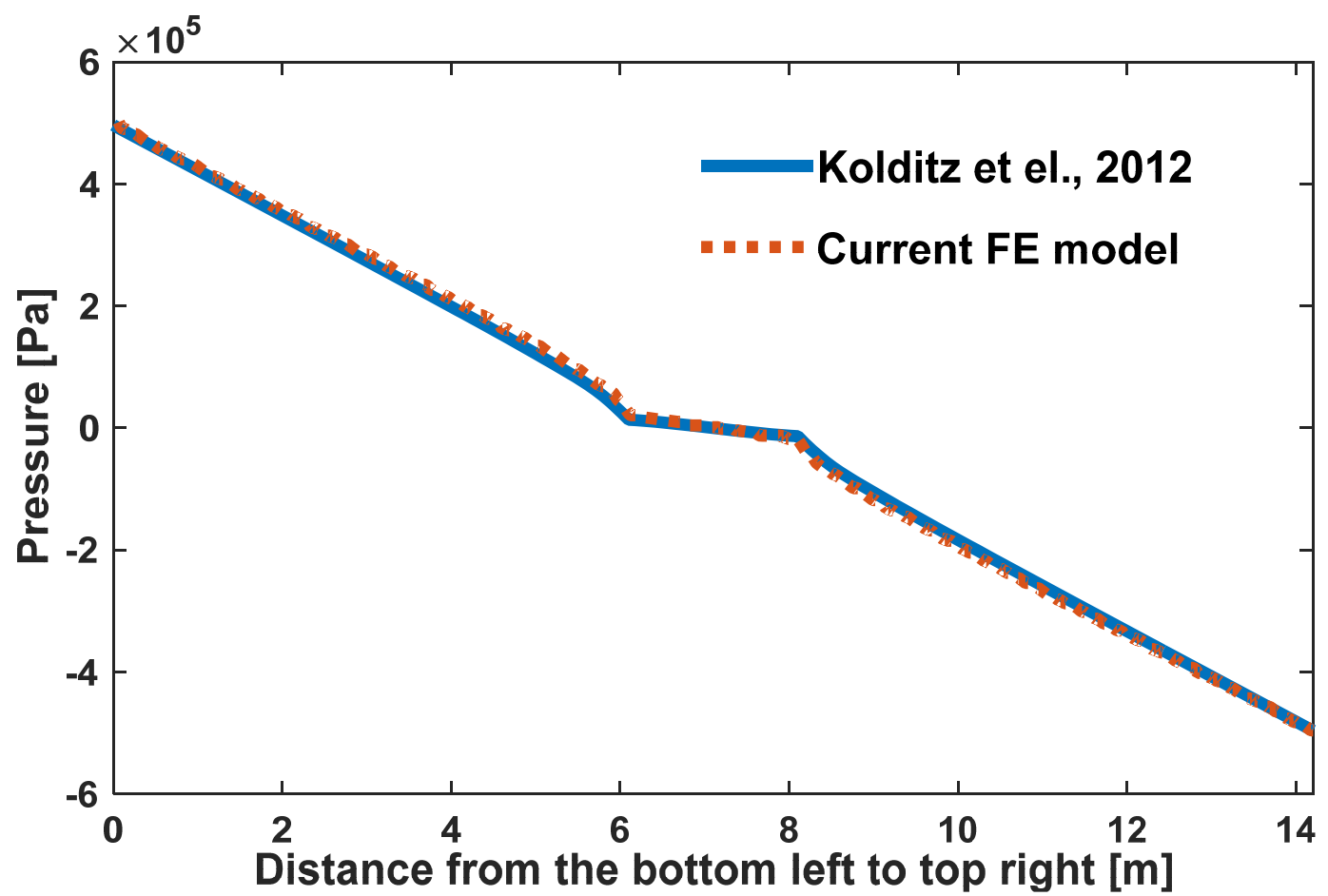

\section{Distance from the bottom left to top right [m]}

921 Figure 4: Pressure profile along a diagonal line from the bottom-left passing via the fracture 


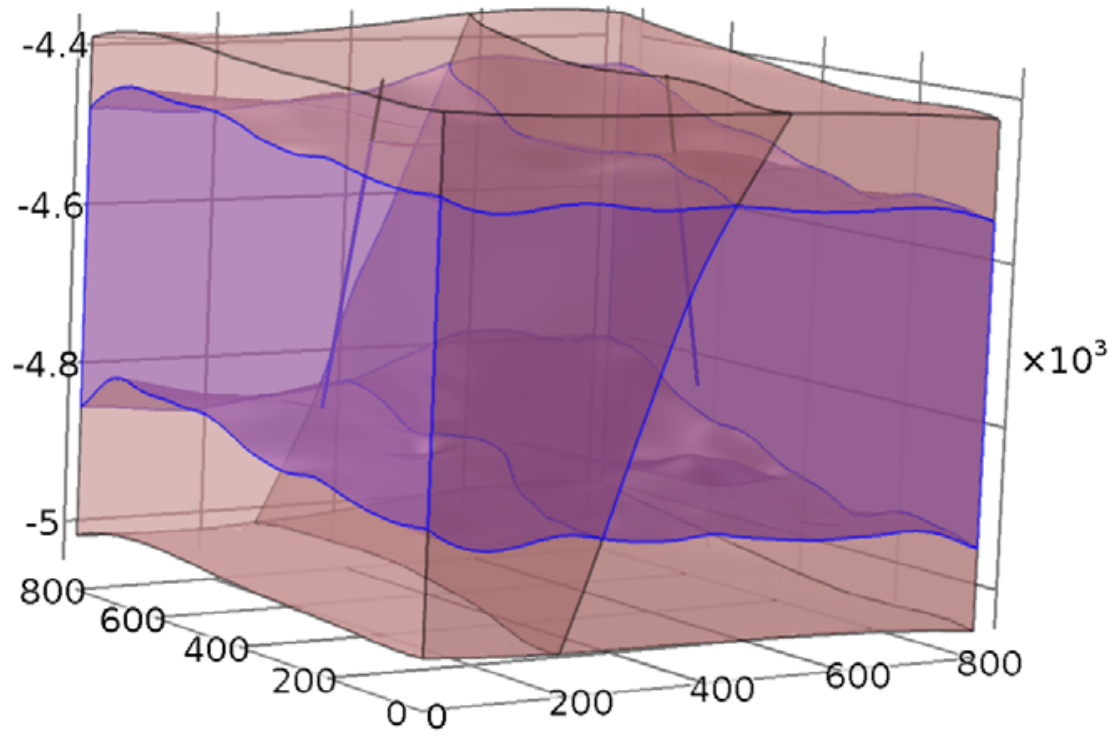

Figure 5(a): Reservoir geometry

930

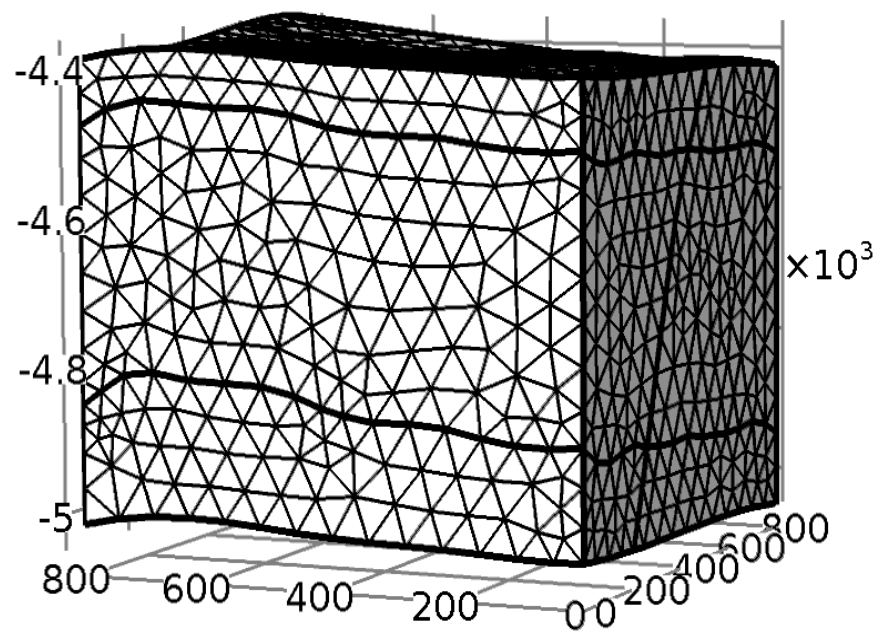

Figure 5(b): Reservoir mesh 


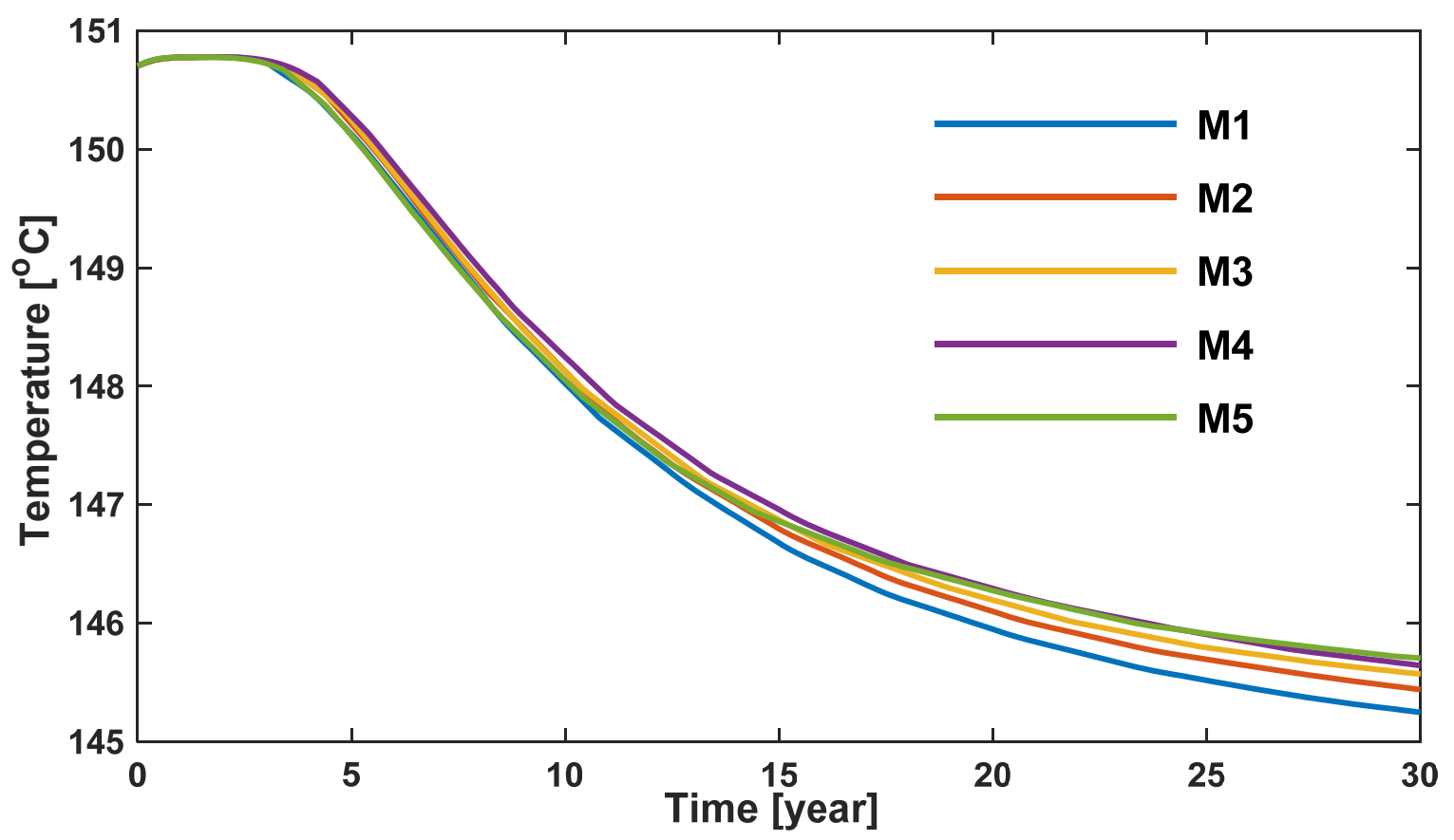

935

936

937

938

939

940

Figure 5(c): Mesh convergence study

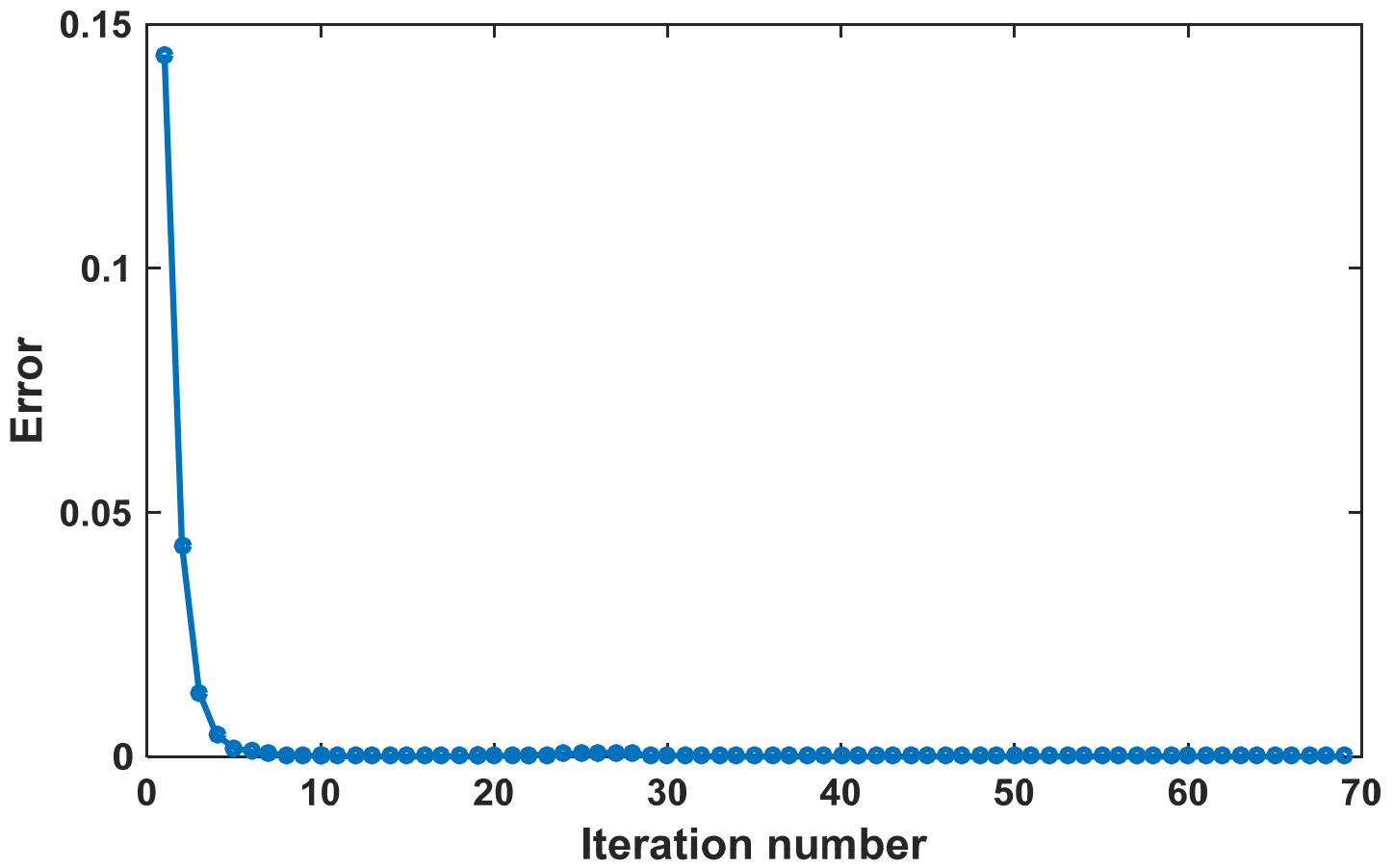

Figure 5(d): Error estimation

Figure 5: Case study of the geothermal reservoir model, mesh with the solution convergence 


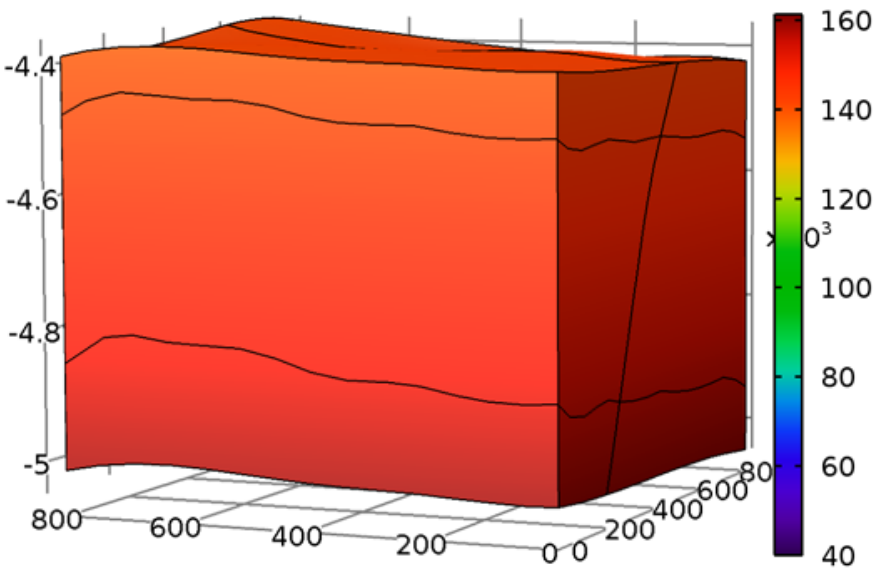

(a) At 0 year

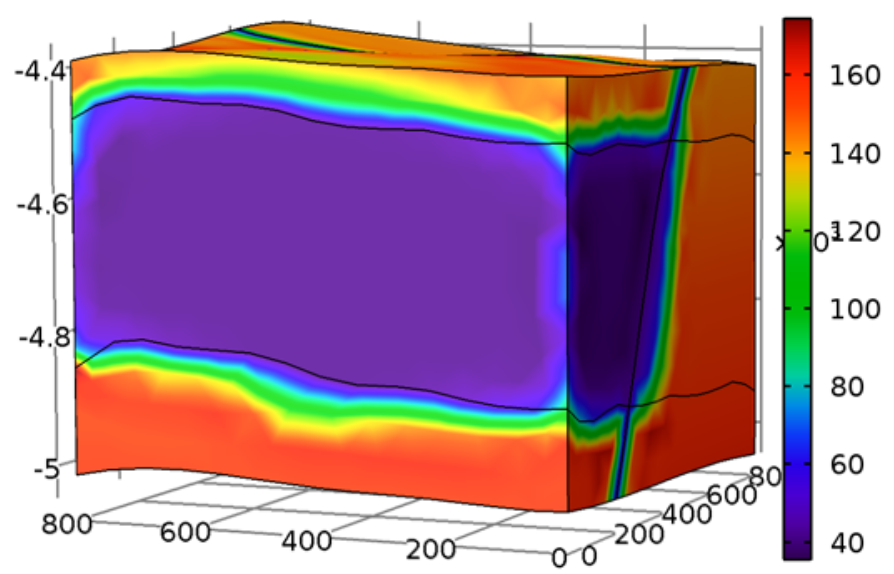

(b) After 15 year

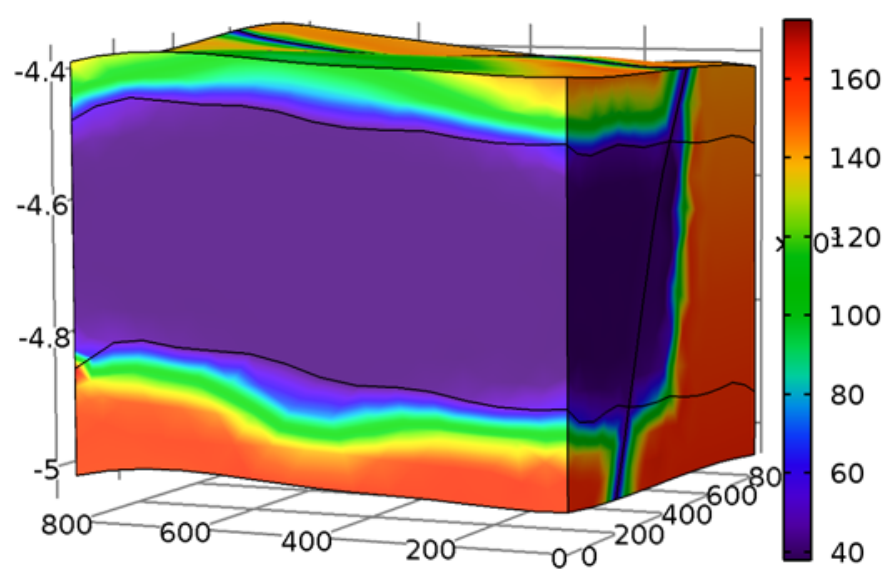

(c) After 30 year 


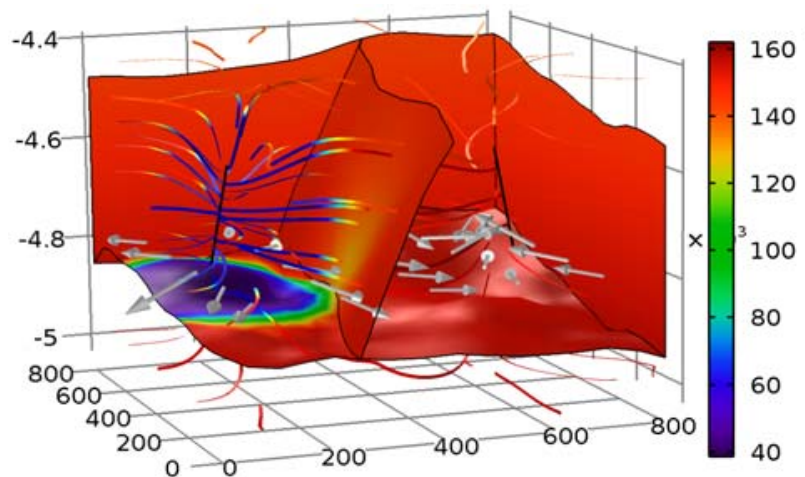

(a) $600 \mathrm{~m}$ well spacing at 1 year

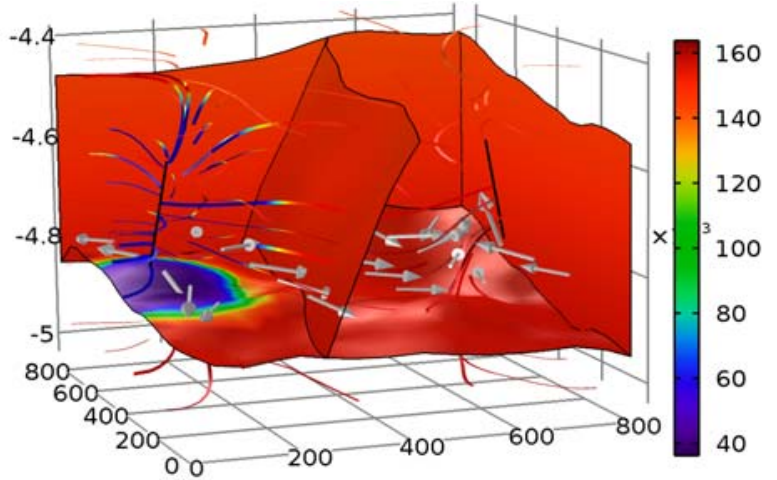

(b) $700 \mathrm{~m}$ well spacing at 1 year

953

954

955

956

957

958

959

960

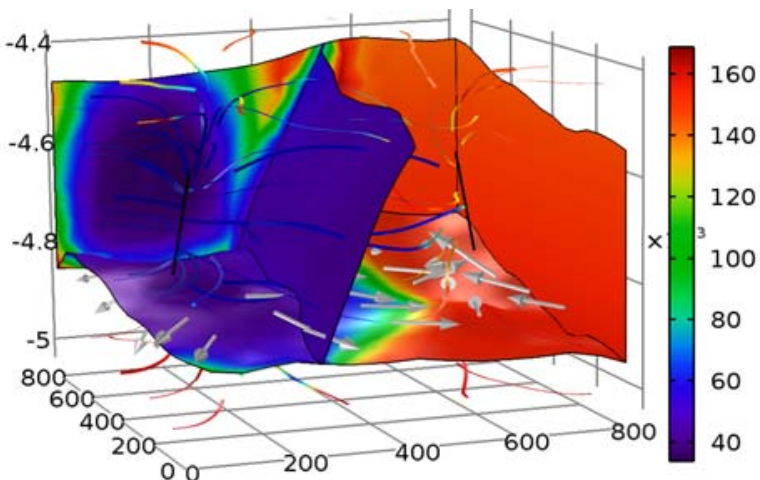

(c) $600 \mathrm{~m}$ well spacing at 15 years

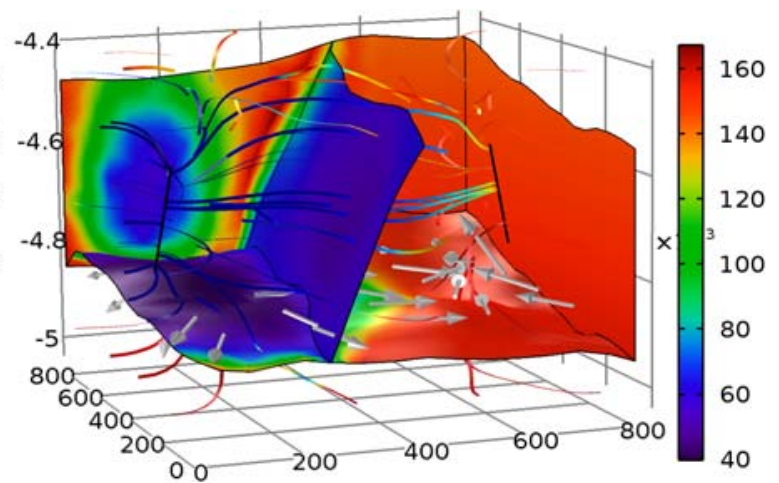

(d) $700 \mathrm{~m}$ well spacing at 15 years

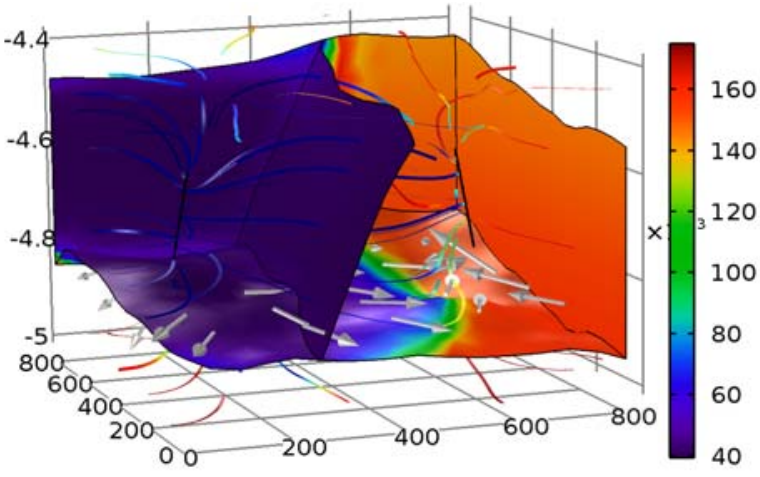

(e) $600 \mathrm{~m}$ well spacing at 30 years

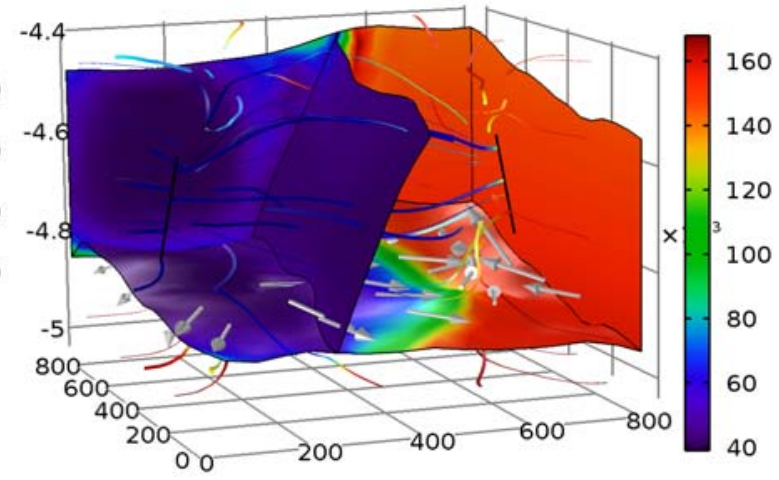

(f) $700 \mathrm{~m}$ well spacing at 30 years

Figure 7: Cold water front propagation within the reservoir $\left({ }^{\circ} \mathrm{C}\right)$ for different well spacing at various stages of simulations 


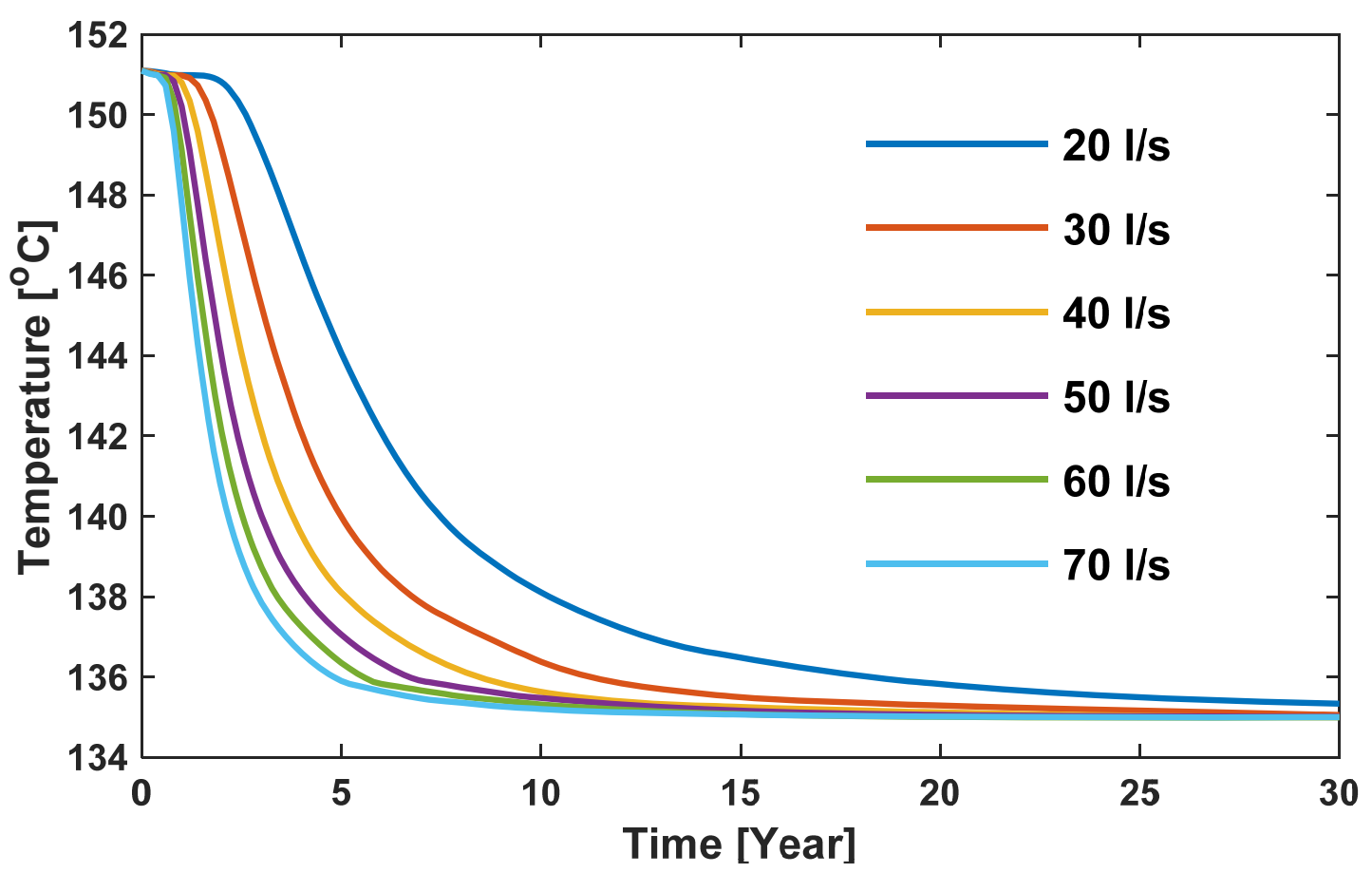

(a) Fluid injection temperature $40^{\circ} \mathrm{C}$ with $600 \mathrm{~m}$ lateral well spacing

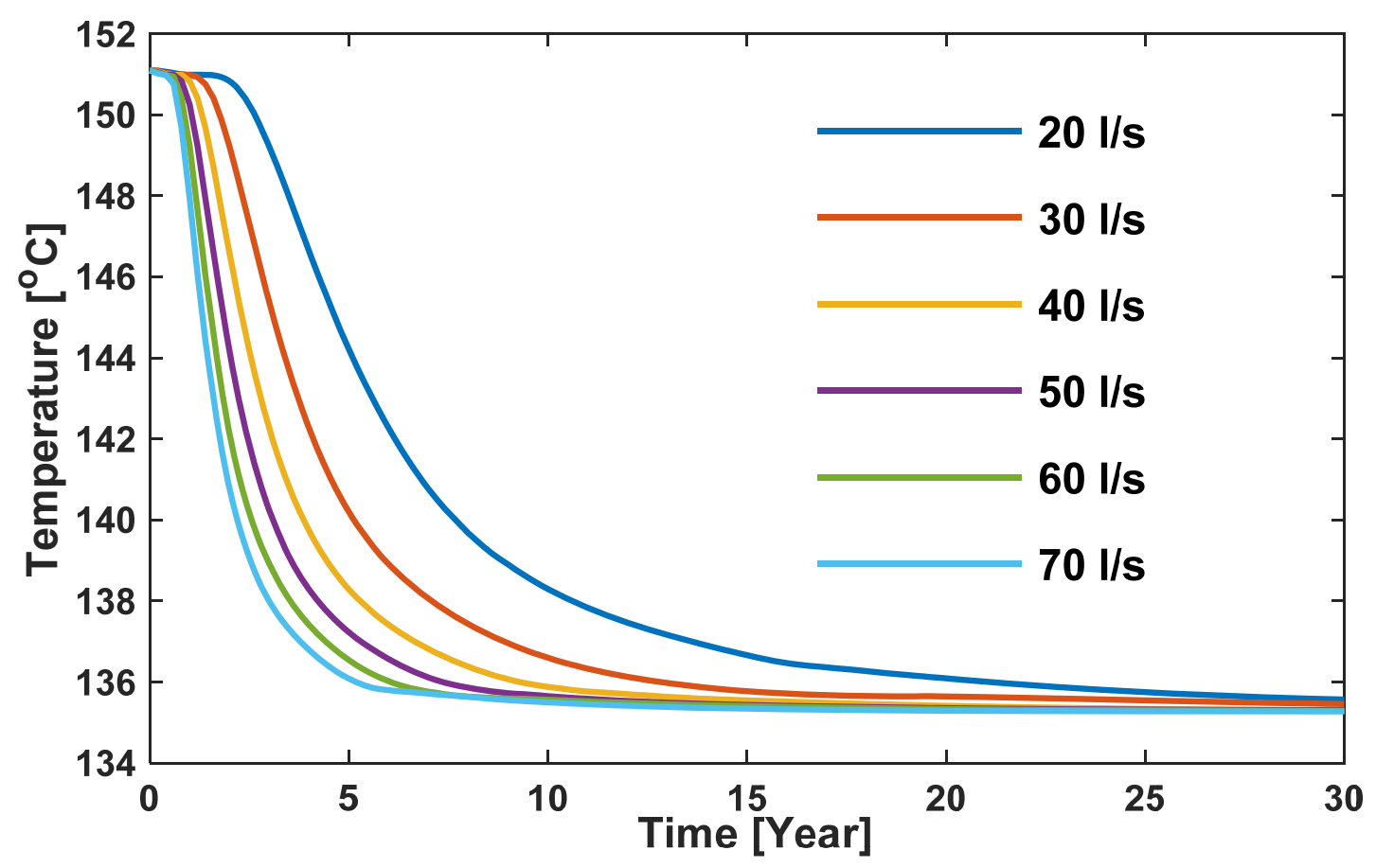

(b) Fluid injection temperature $50^{\circ} \mathrm{C}$ with $600 \mathrm{~m}$ lateral well spacing

967 


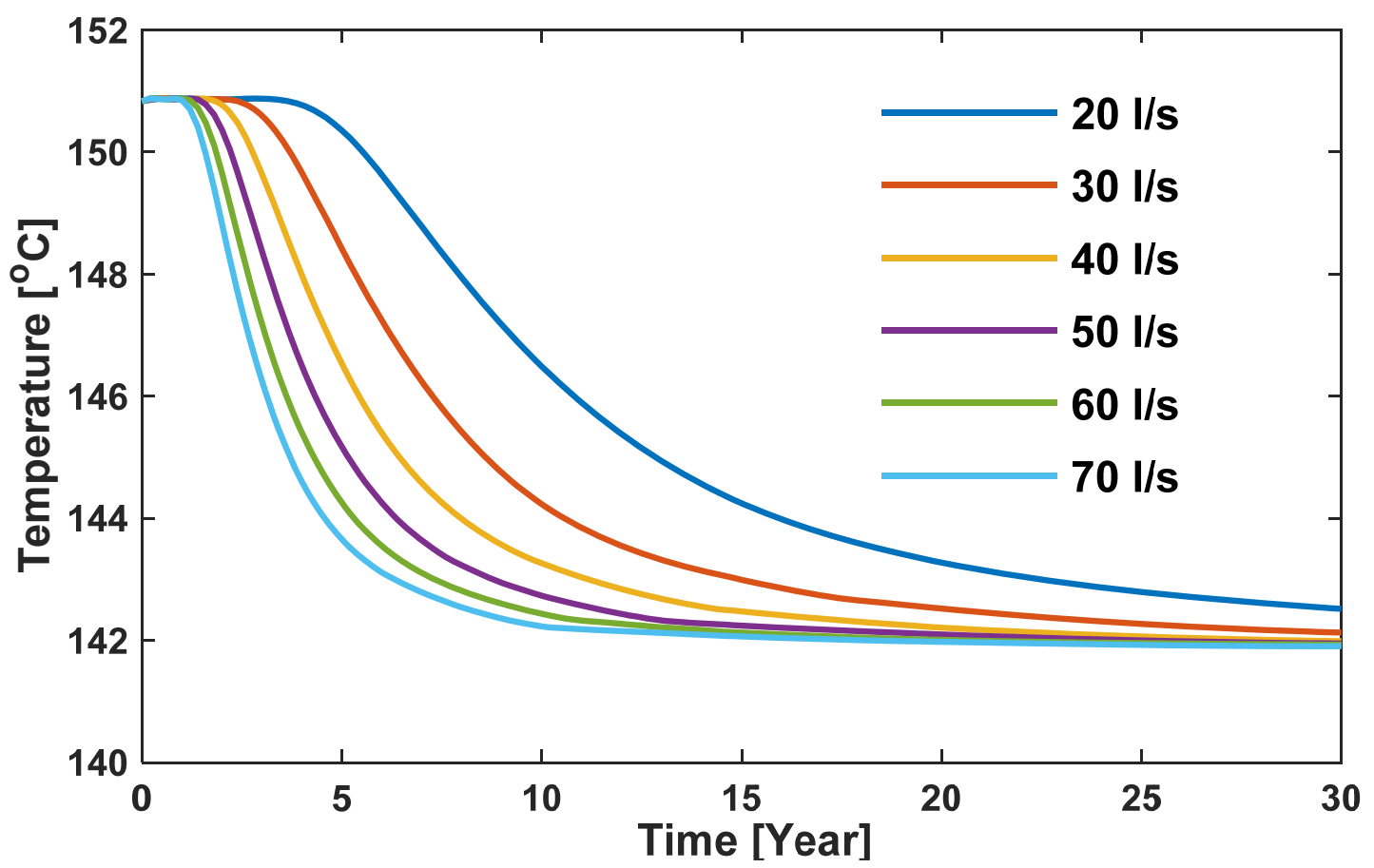

(c) Fluid injection temperature $40^{\circ} \mathrm{C}$ with $700 \mathrm{~m}$ lateral well spacing

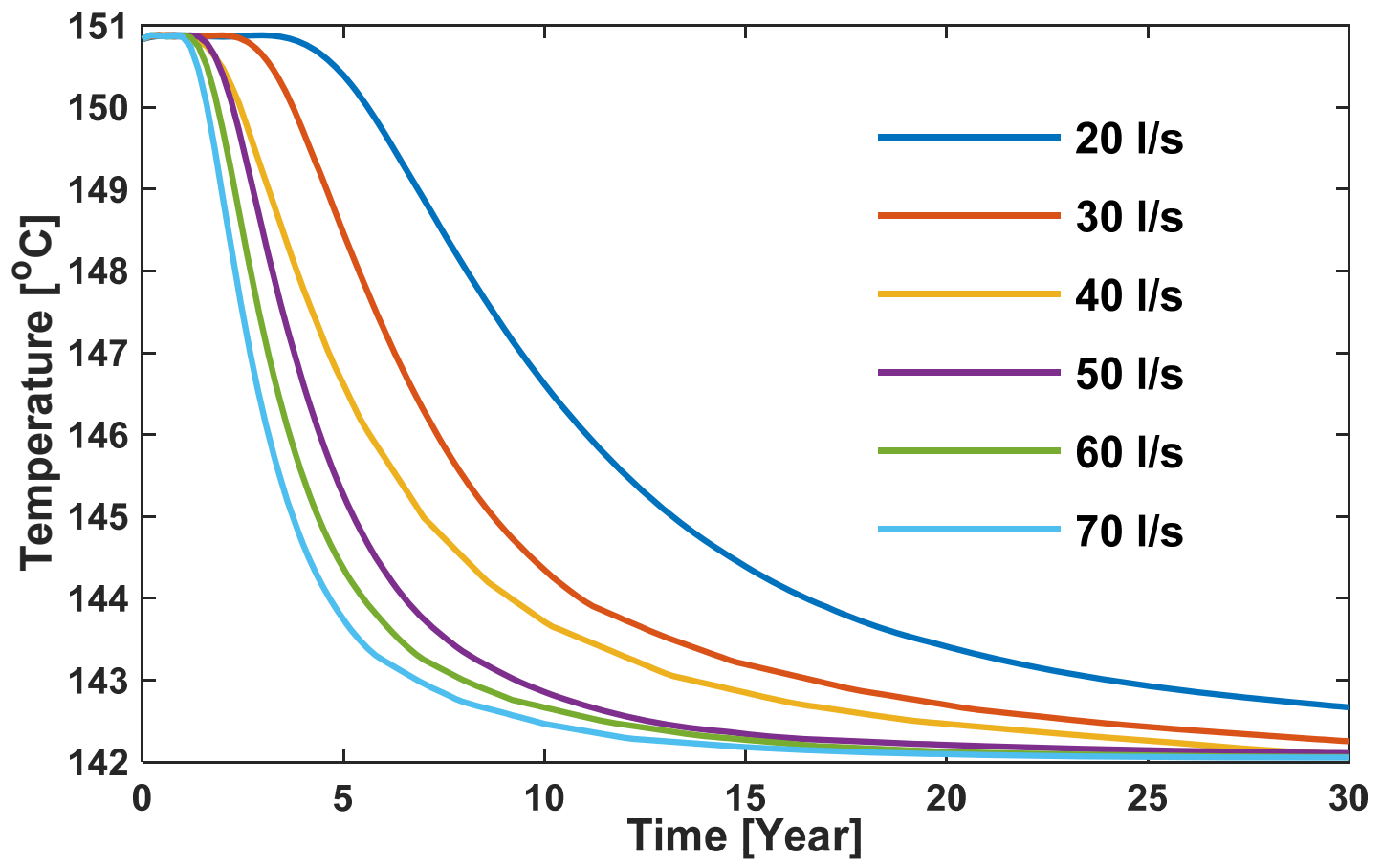

971

972

973

974

(d) Fluid injection temperature $50^{\circ} \mathrm{C}$ with $700 \mathrm{~m}$ lateral well spacing

Figure 8: Production wellhead temperature under the effect of various injection flow rate ranging from 20 to $70 \mathrm{l} / \mathrm{s}$ 


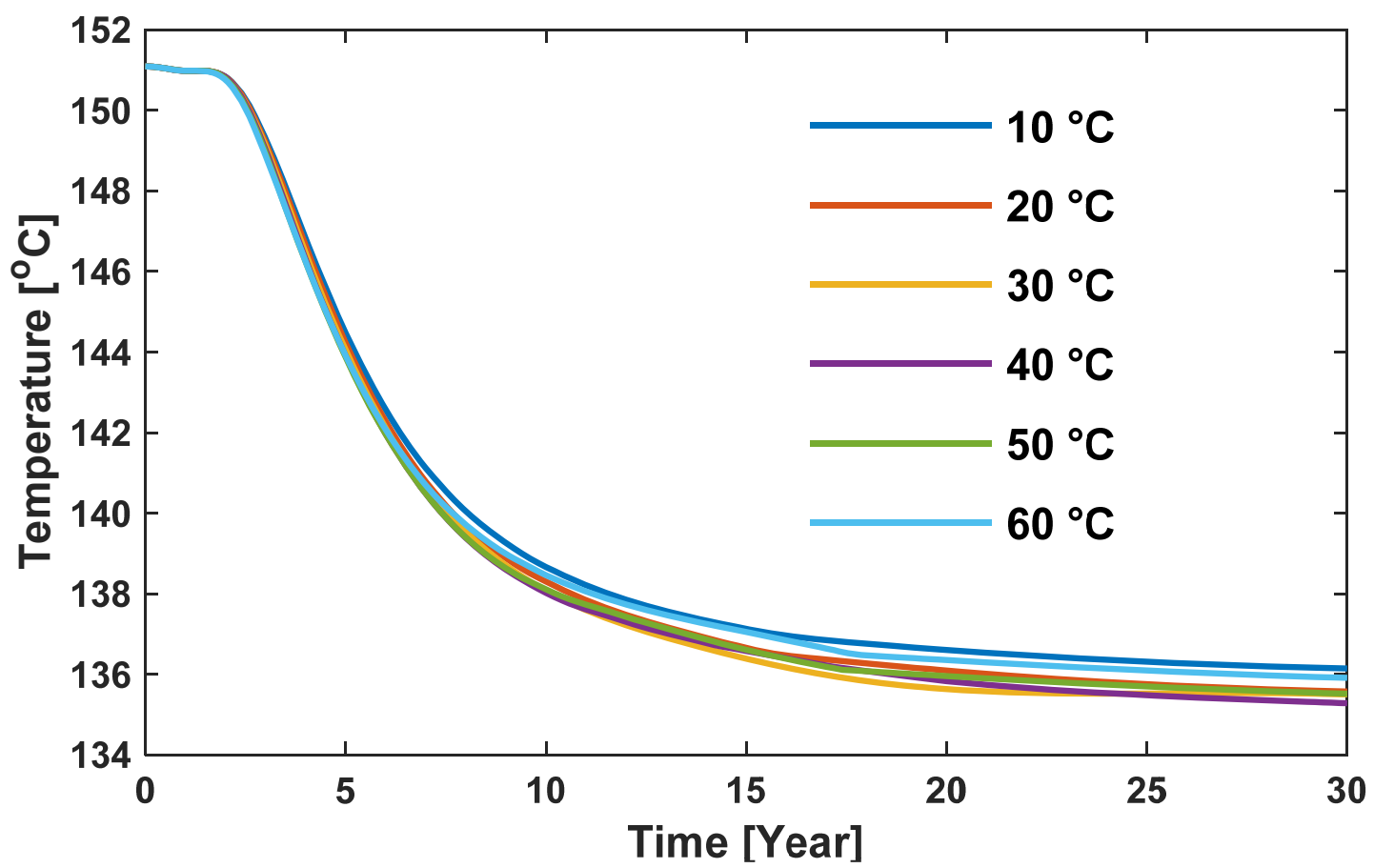

978

(a) Fluid injection rate $20 \mathrm{l} / \mathrm{s}$ with $600 \mathrm{~m}$ lateral well spacing

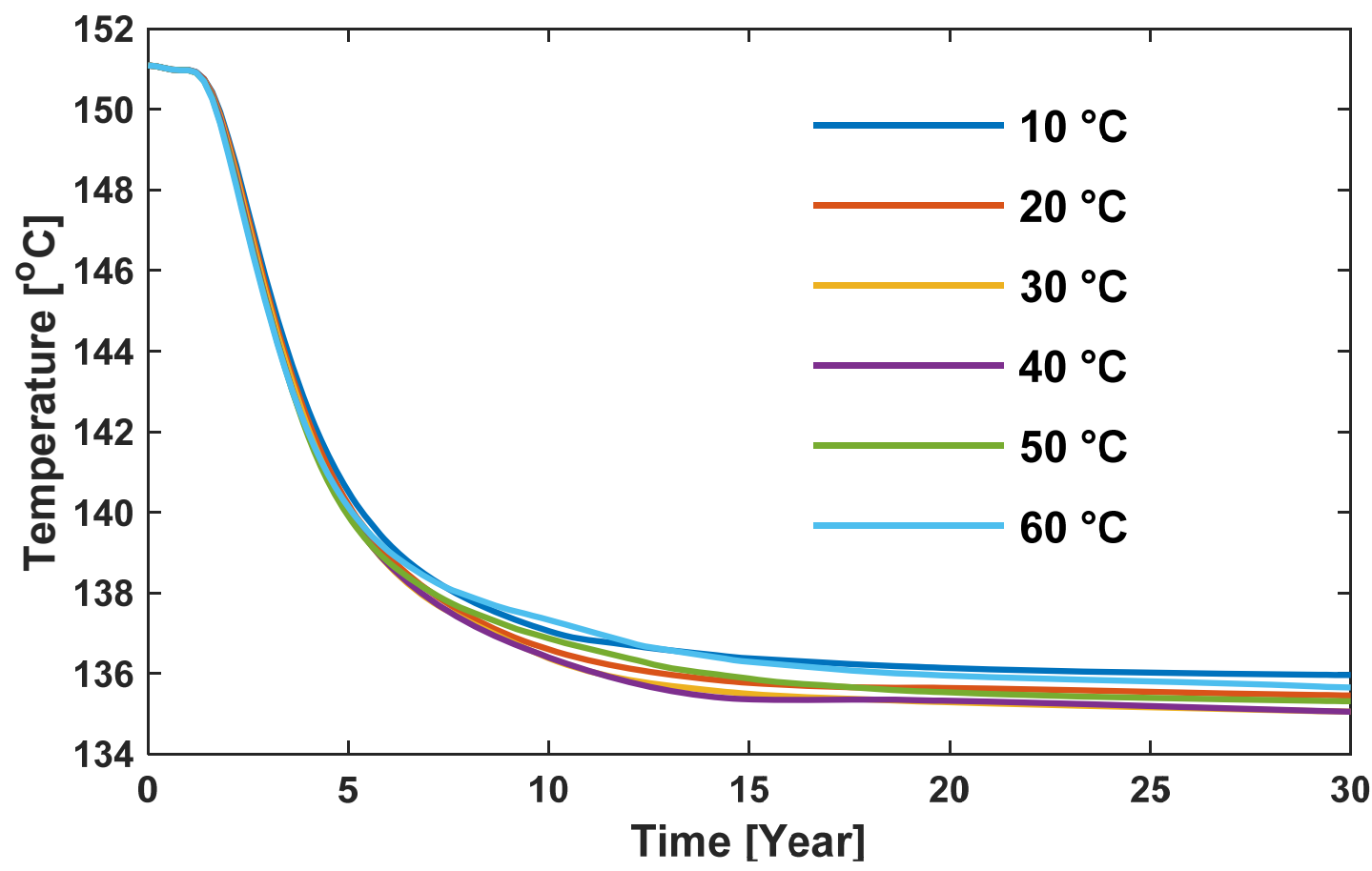

(b) Fluid injection rate $30 \mathrm{l} / \mathrm{s}$ with $600 \mathrm{~m}$ lateral well spacing 


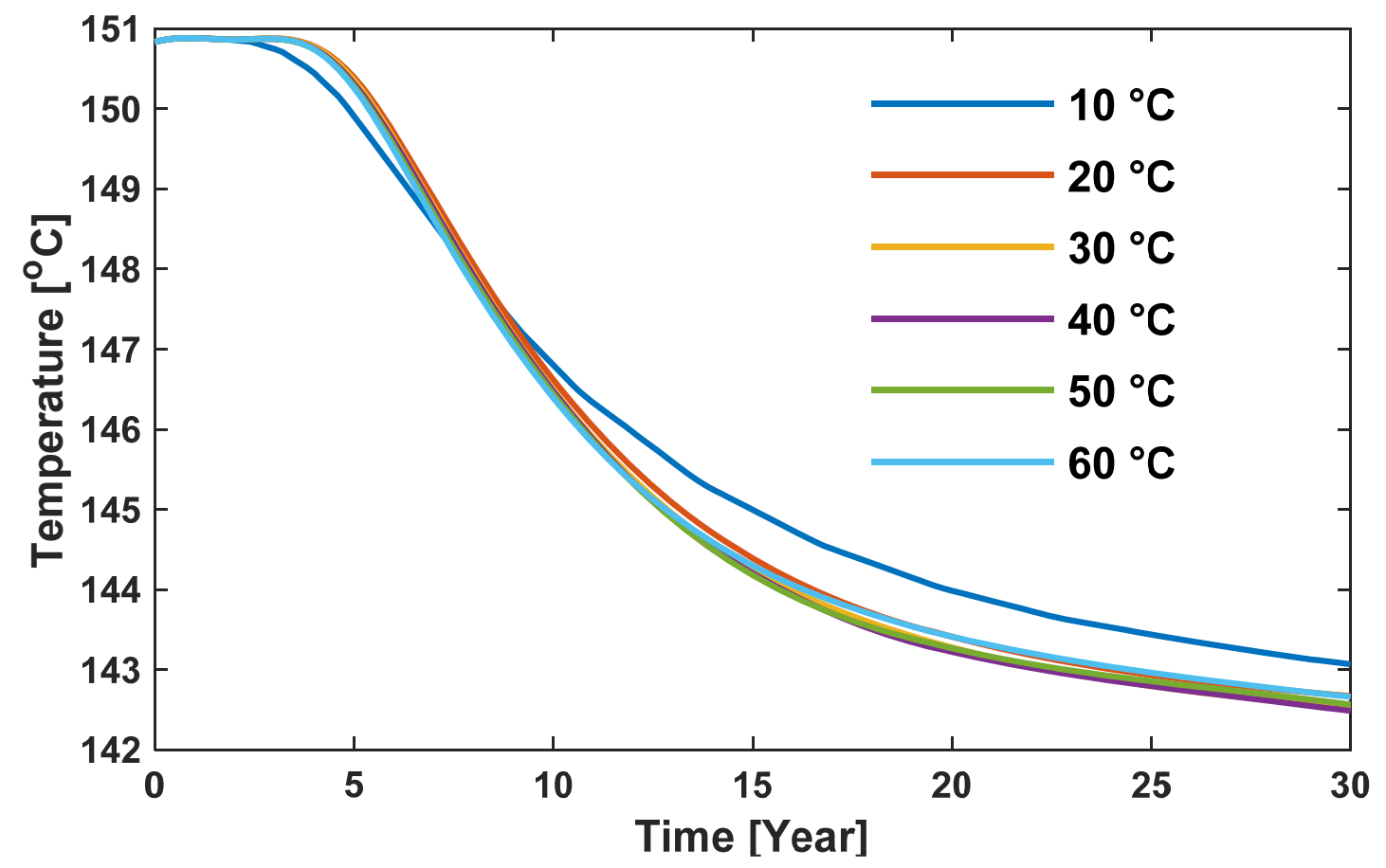

982

(c) Fluid injection rate $201 / \mathrm{s}$ with $700 \mathrm{~m}$ lateral well spacing

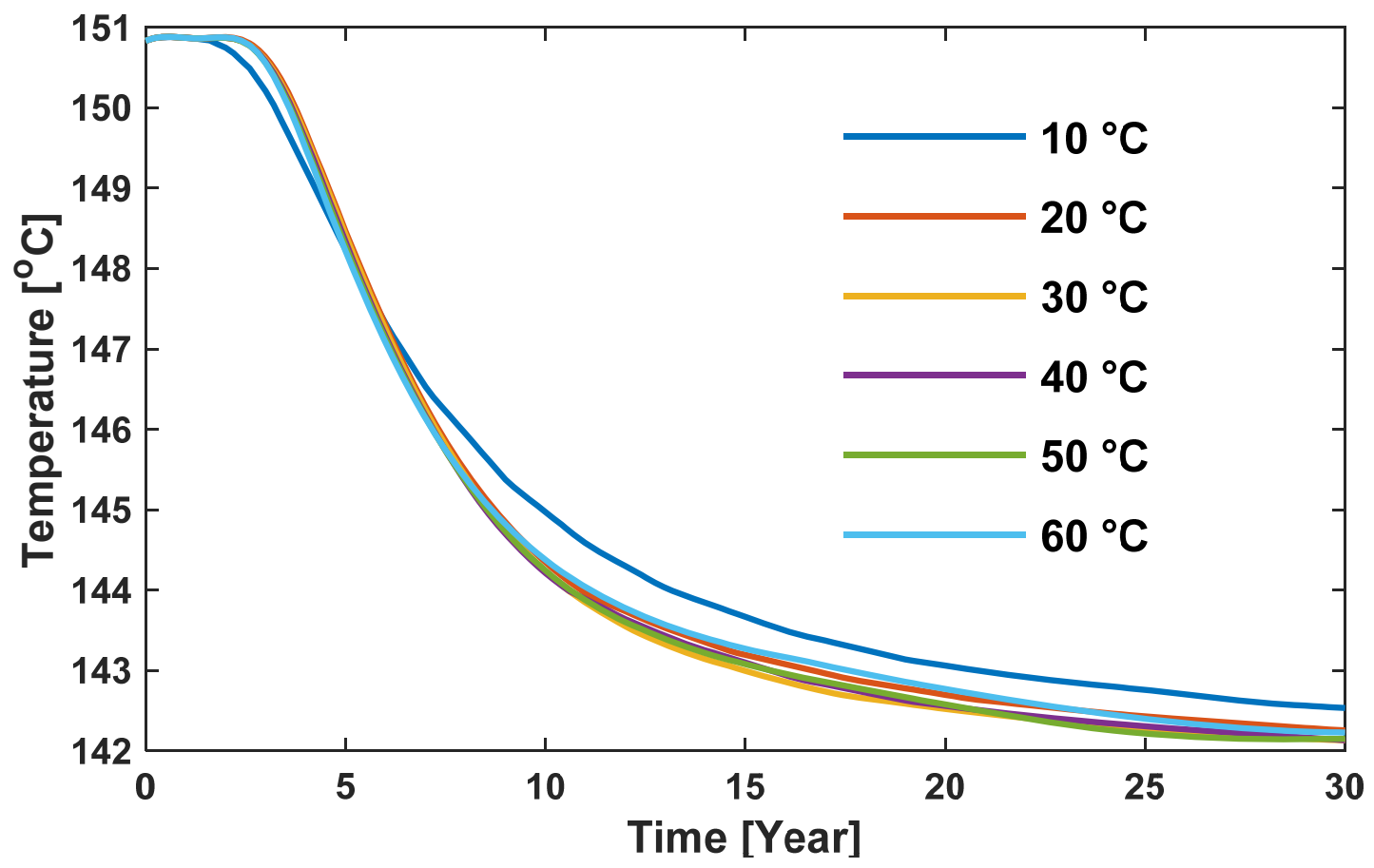

(d) Fluid injection rate $30 \mathrm{l} / \mathrm{s}$ with $700 \mathrm{~m}$ lateral well spacing

Figure 9: Production temperature over time due to the effect of various injection fluid 


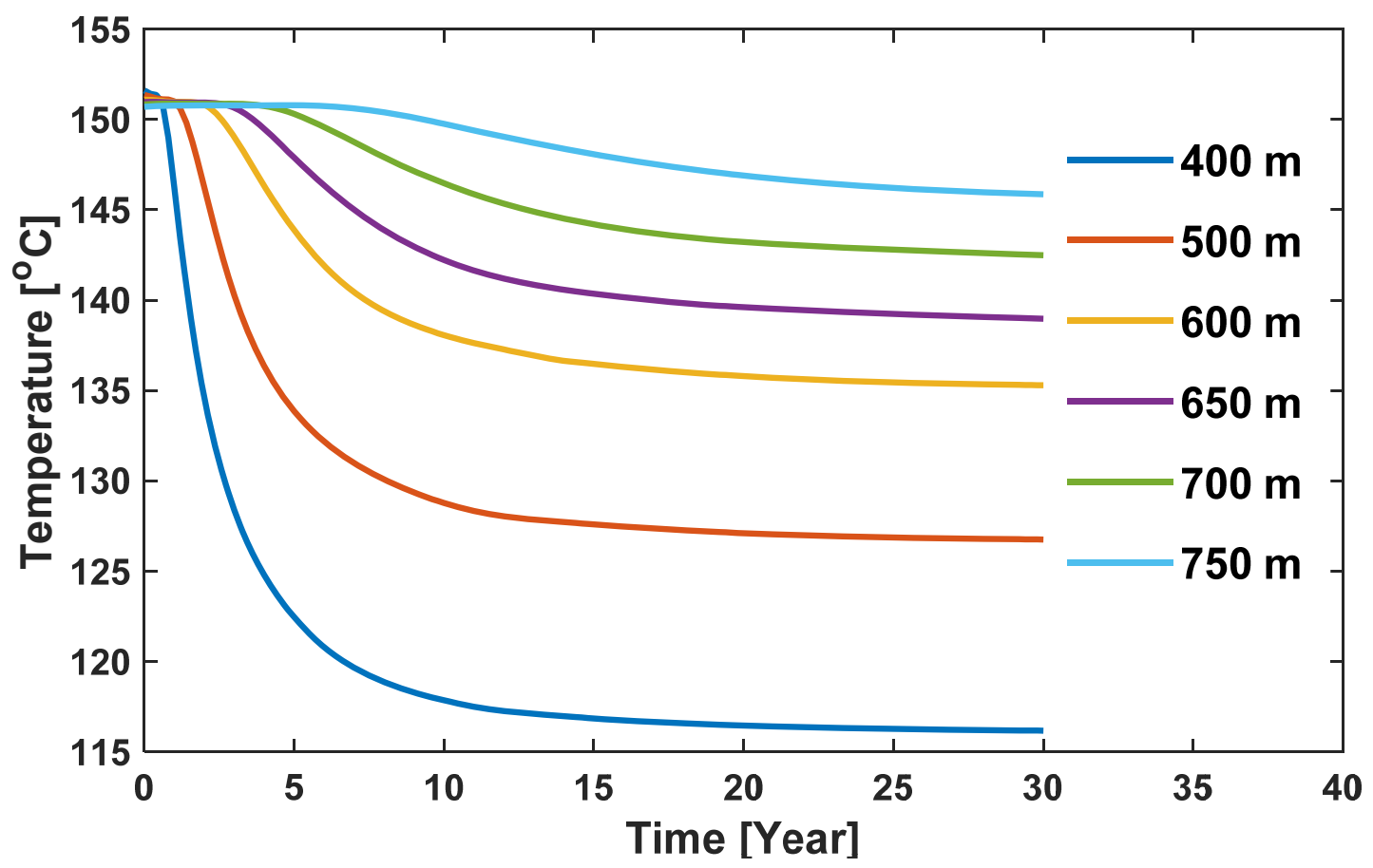

989

(a) Fluid injection rate $20 \mathrm{l} / \mathrm{s}$ with $30^{\circ} \mathrm{C}$ injection fluid temperature

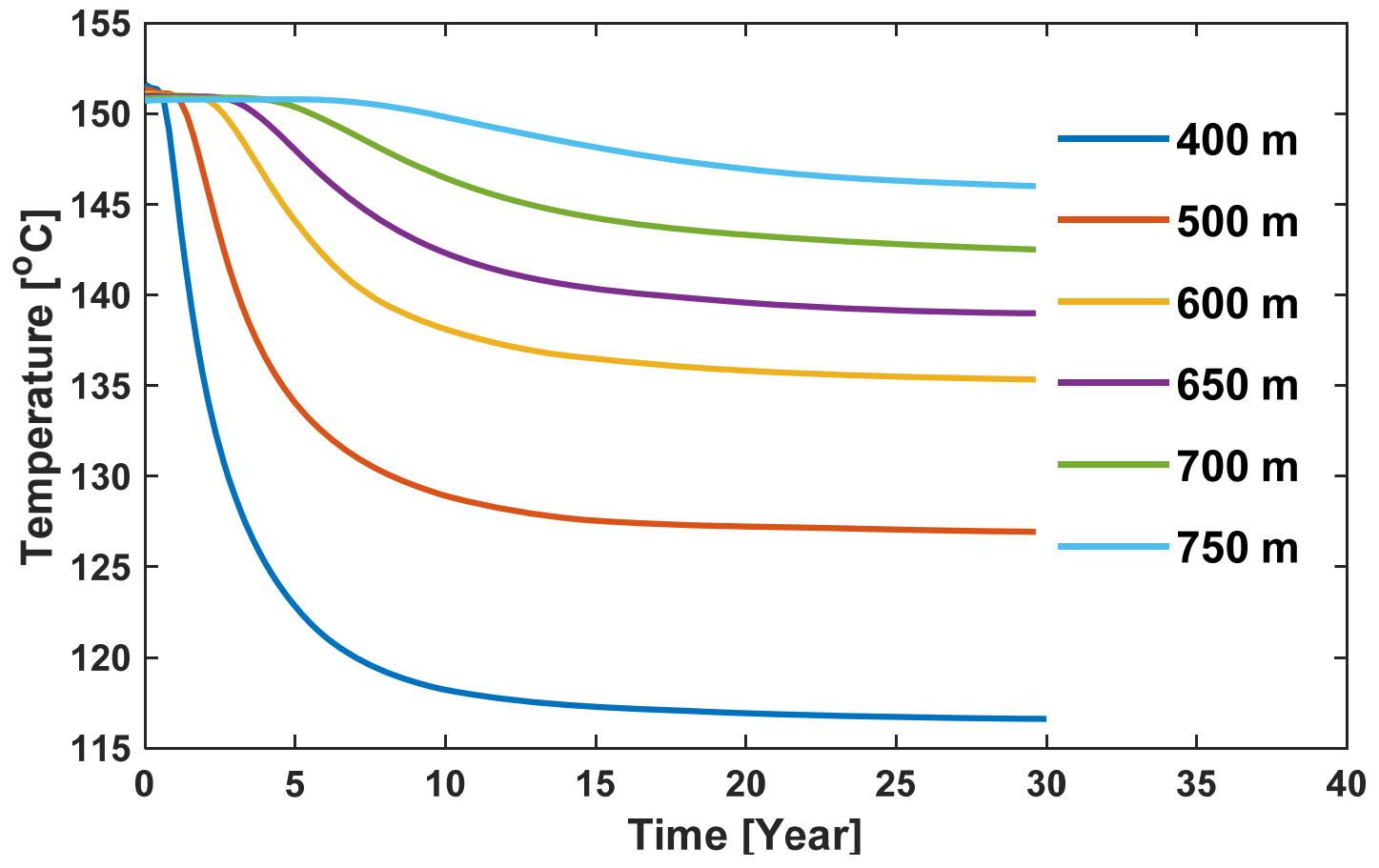

991

(b) Fluid injection rate $20 \mathrm{l} / \mathrm{s}$ with $40^{\circ} \mathrm{C}$ injection fluid temperature

993 


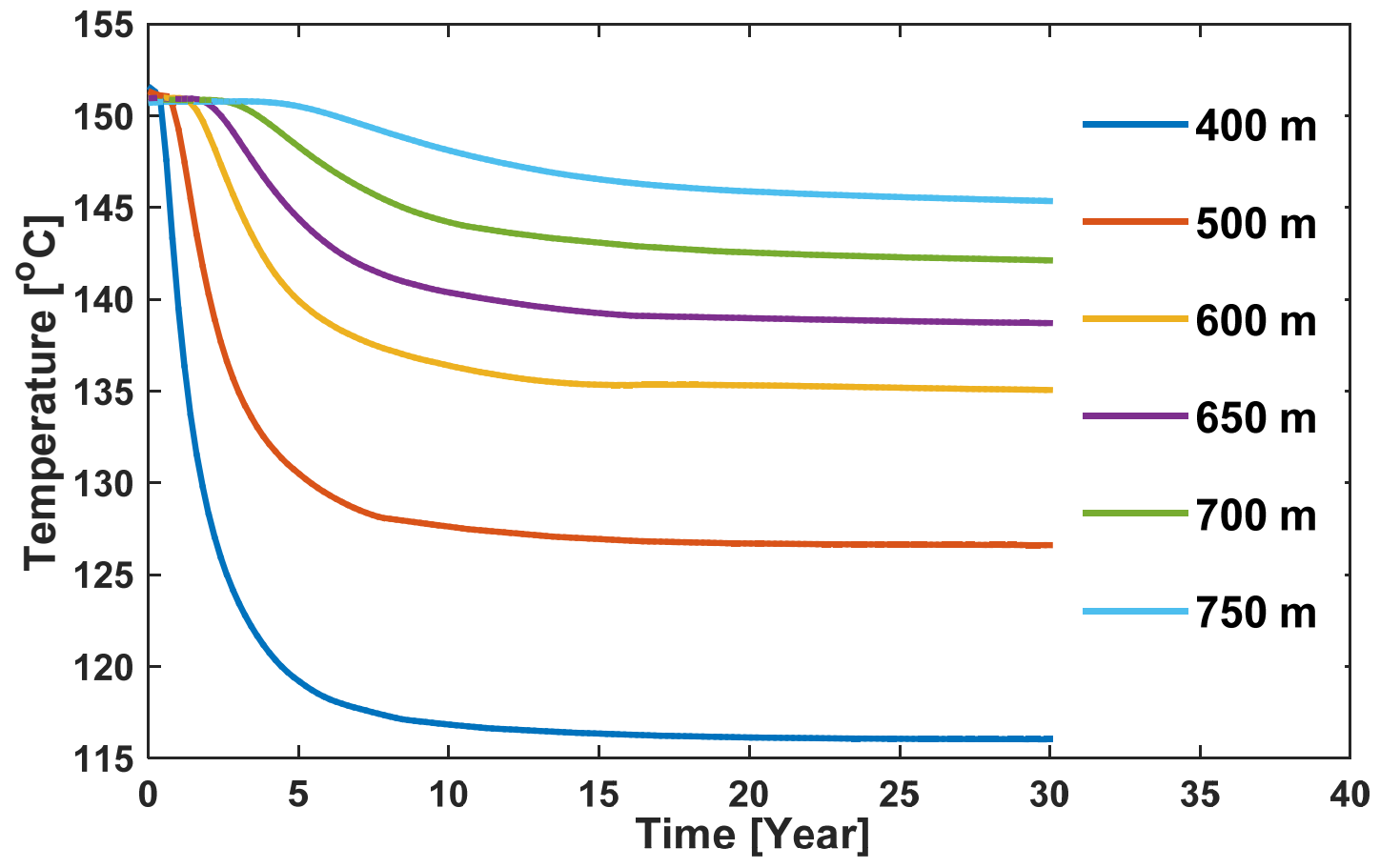

994

995

(c) Fluid injection rate $30 \mathrm{l} / \mathrm{s}$ with $30^{\circ} \mathrm{C}$ injection fluid temperature

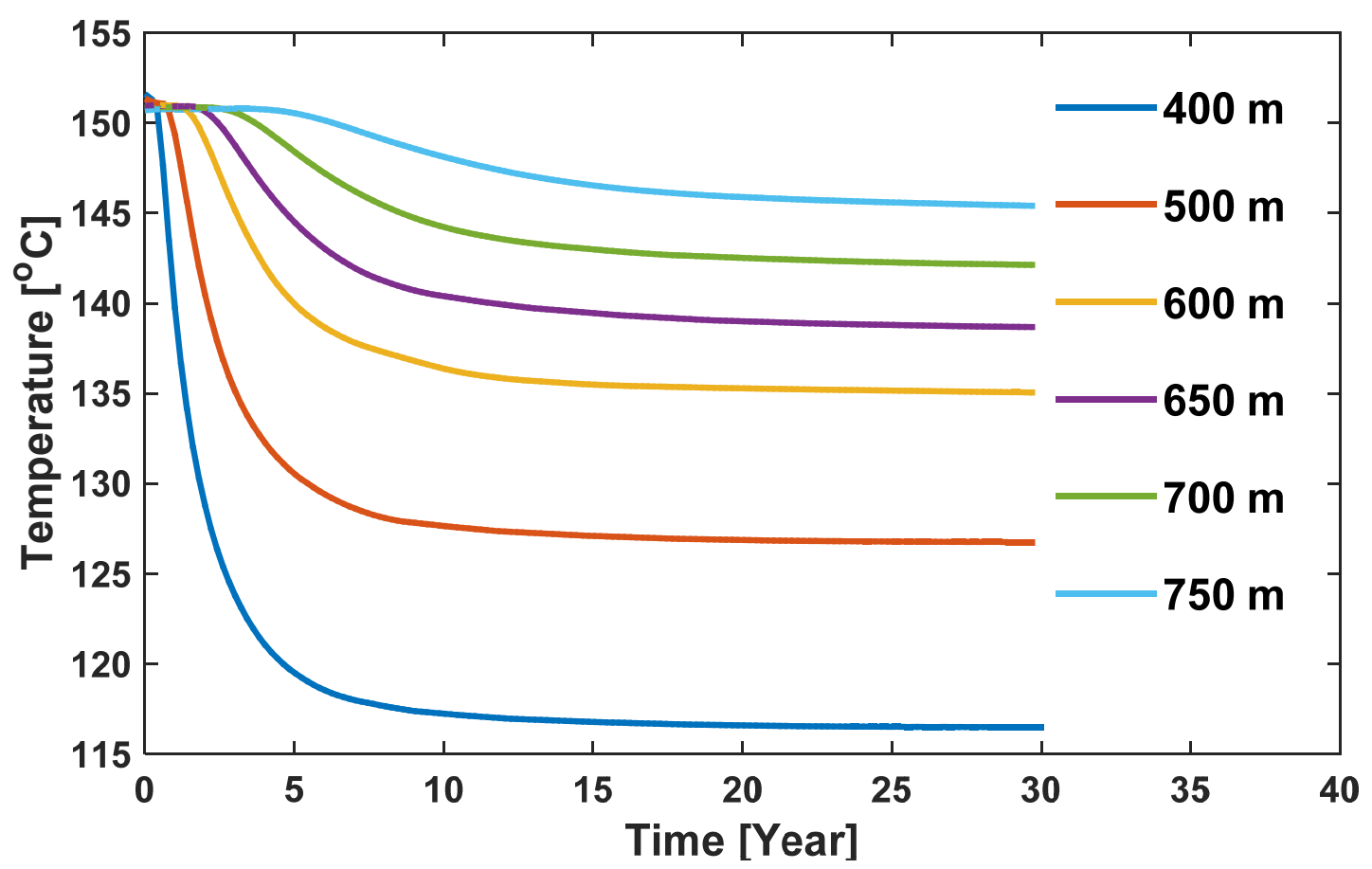

(d) Fluid injection rate $30 \mathrm{l} / \mathrm{s}$ with $40^{\circ} \mathrm{C}$ injection fluid temperature

998 Figure 10: Production temperature over time due to the effect of various lateral well spacing 


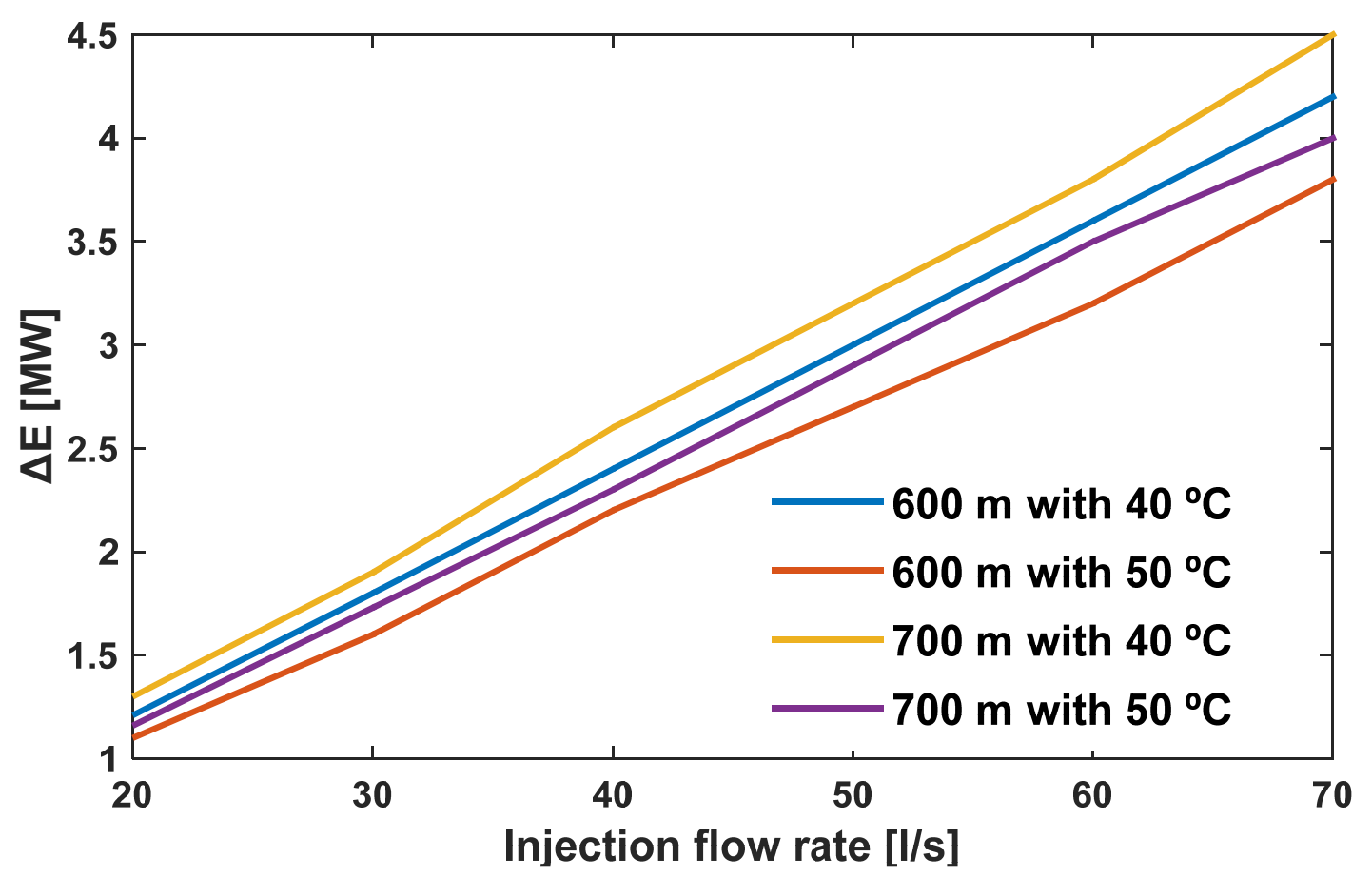

999

1000

1001

1002

1003

1004

1005
Figure 11: Production energy as function of fluid injection rate under different lateral well spacing and fluid injection temperatures

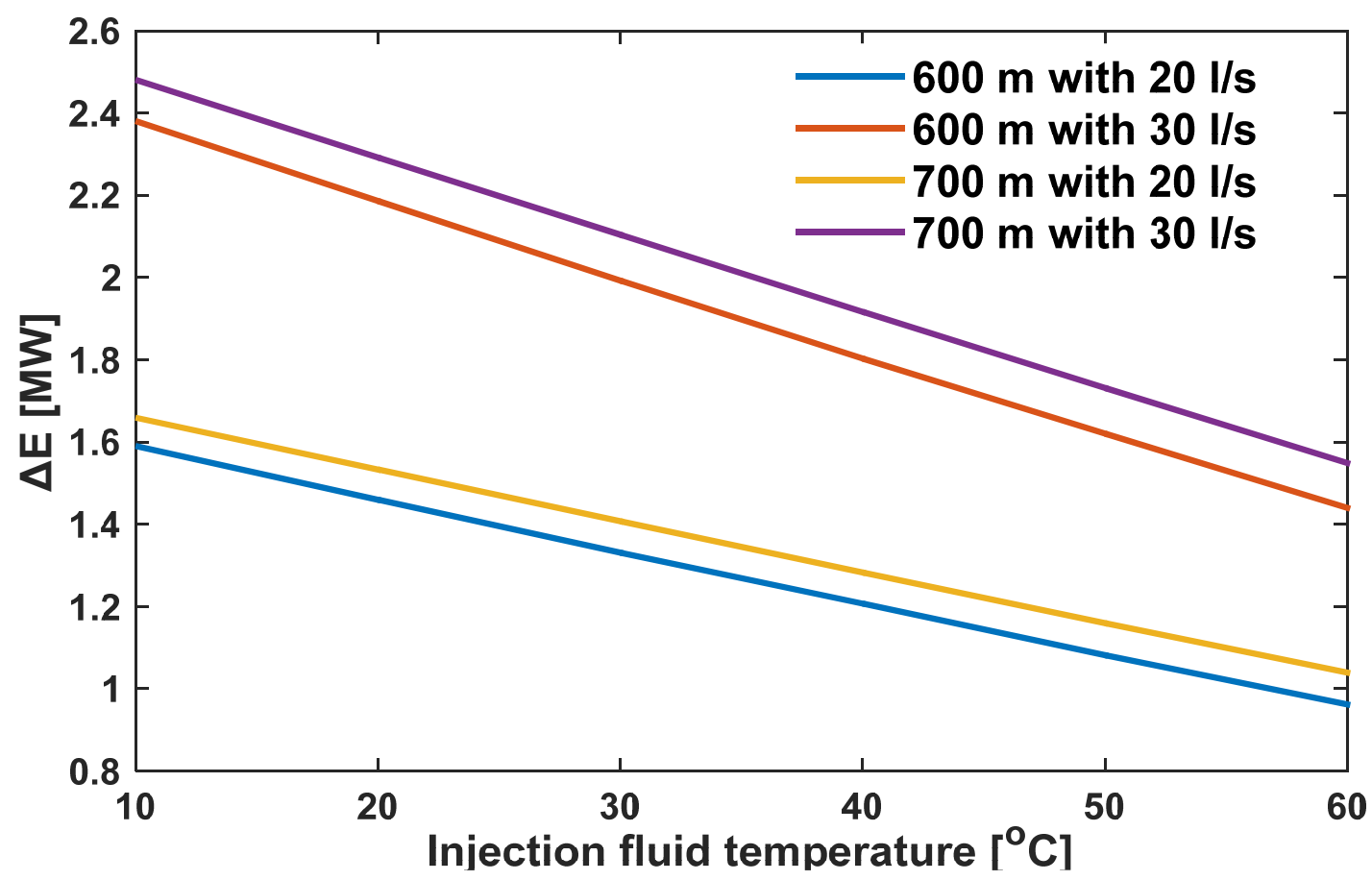

Figure 12: Production energy as function of fluid injection temperature under different lateral well spacing and fluid injection rates 


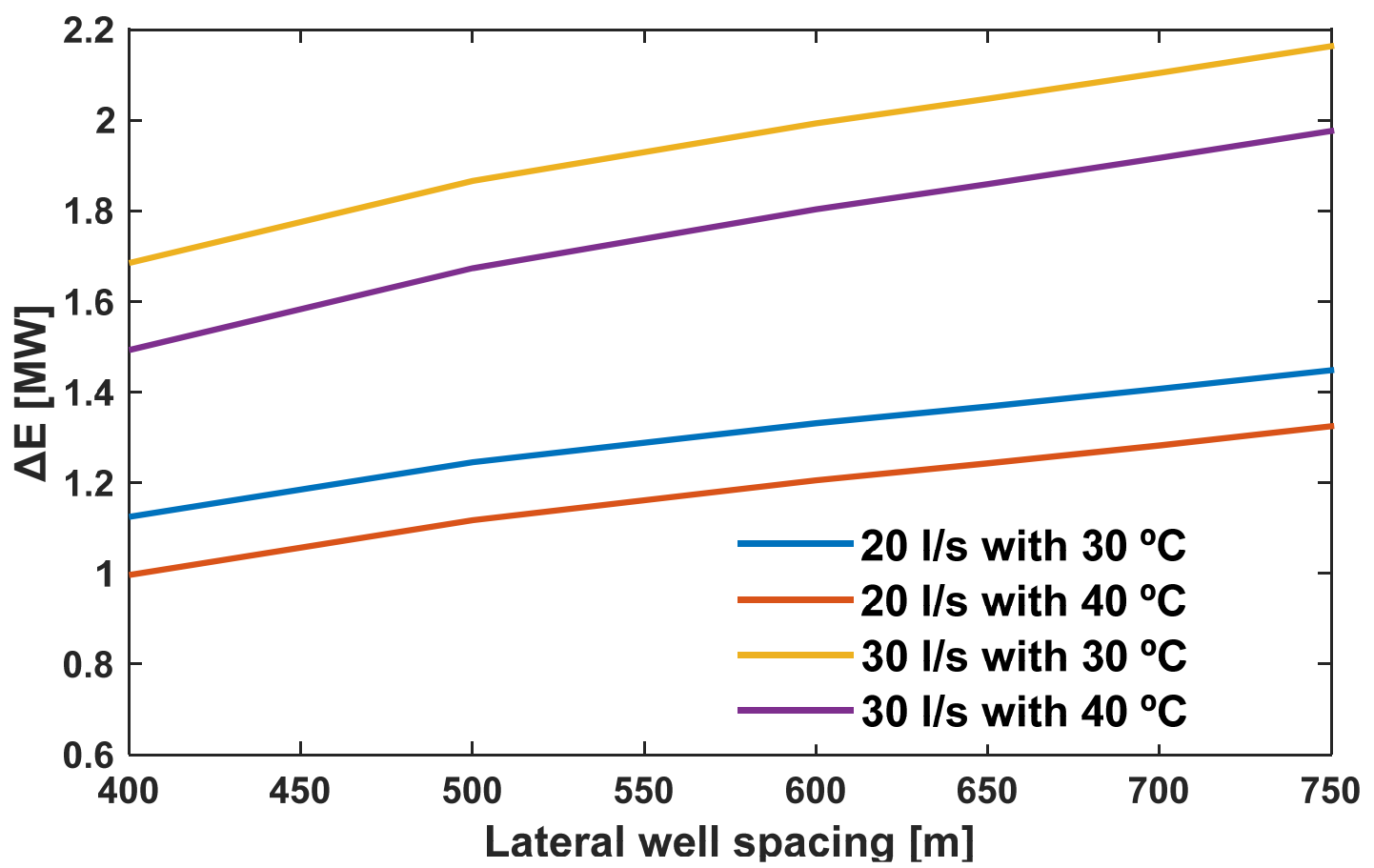

Figure 13: Production energy as function of lateral well spacing under different injection

1015

1016

1017 